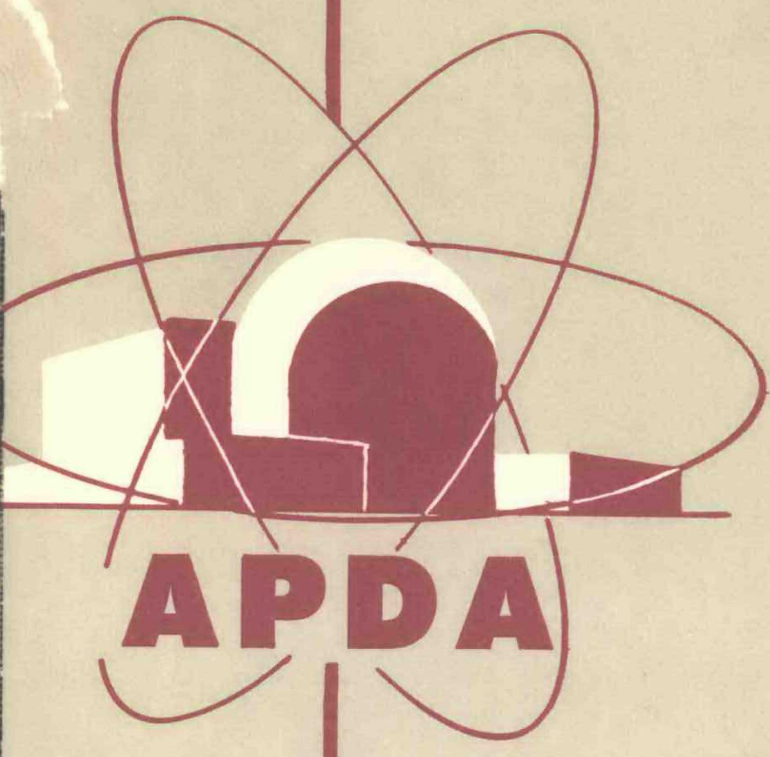

\title{
CONCEPTS FOR GENERAL-PURPOSE UNDER SODIUM SCANNING SYSTEMS
}

AEC Contract No. AT(11-1) -865

Project Agreement No. 14

Liquid Metal Cooled Reactors Branch

RSTBASND FOR ANNOUNCEMENT TN MUCTRAR SCLENCE ABSTRAGTS
Shuh-Pan Ying

Clyde C. Scott

\section{ATOMIC \\ POWER DEVELOPMENT ASSOCIATES, INC.}




\section{DISCLAIMER}

This report was prepared as an account of work sponsored by an agency of the United States Government. Neither the United States Government nor any agency Thereof, nor any of their employees, makes any warranty, express or implied, or assumes any legal liability or responsibility for the accuracy, completeness, or usefulness of any information, apparatus, product, or process disclosed, or represents that its use would not infringe privately owned rights. Reference herein to any specific commercial product, process, or service by trade name, trademark, manufacturer, or otherwise does not necessarily constitute or imply its endorsement, recommendation, or favoring by the United States Government or any agency thereof. The views and opinions of authors expressed herein do not necessarily state or reflect those of the United States Government or any agency thereof. 


\section{DISCLAIMER}

Portions of this document may be illegible in electronic image products. Images are produced from the best available original document. 


\section{LEGAL NOTICE}

This report was prepared as an account of Government sponsored work. Neither the United States nor the Commission, nor any person acting on behalf of the Commission:

A. Makes any warranty or representation expressed or implied, with respect to the accuracy, completeness, or usefulness of the information contained in this report, or that the use of any information, apparatus, method, or process disclosed in this report may not infringe privately owned rights; or

B. Assumes any liabilities with respect to the use of, or for damages resulting from the use of any information, apparatus, method, or process diselosed in this report.

As used in the above, "person acting on behalf of the commission" includes any employee or contractor of the Commission, or employee of such contractor, to the extent that such employee or contractor of the Commission, or employee of such contractor prepares disseminates, or provides access to, any information pursuant to his employment or contract with the Commission, or his employment with such contractor. 


\title{
LEG A L NOTICE
}

This report was prepared as an account of Government sponsored work. Neither the United States, nor the Commission, nor any person acting on behalf of the Commission:

A. Makes any warranty or representation, expressed or implied, with respect to the accuracy, completeness, or usefuiness of the information contained in this report, or that the use of any information, apparatus, method, or process disciosed in this report may not infringe privately owned rights; or

B. Assumes any liabilitles with respect to the use of, or for damages resulting from the use of any information, apparatus, method, or process disclosed in this report.

As used in the above, "person acting on behalf of the Commission" includes any employee or contractor of the commission, or employee of such contractor, to the extent that such employee or contractor of the Commission, or employee of such contractor prepares, disaemin or provides acos to any information pursuat to his employment or contract

with the Commission, or his employment with such contractor.

\section{CONCEPTS FOR GENERAL-PURPOSE UNDER SODIUM SCANNING SYSTEMS}

\author{
AEC Contract No. AT( $11-1)-865$ \\ Project Agreement No. 14 \\ Liquid Metal Cooled Reactors Branch
}

Shuh-Pan Ying

Clyde C. Scott

REIBASED FOR ANNOUNCENENT

IN NUCHEAR SCIENCE ABSTRACTS 


\begin{abstract}
The development of the concepts for general-purpose scanning systems is discussed, based on the consideration of ultrasonics operating in liquid sodium. Technical information and data, such as ultrasonic attenuation in liquid sodium, piezoelectric materials operating in $600 \mathrm{~F}$ sodium, etc., are provided from theoretical and experimental studies. The report also includes the explanations, analyses, and applications of the single-narrowbeam scanning systems and the electronic acoustic image conversion methods.
\end{abstract}


TABLE OF CONTENTS

$\underline{\text { Page }}$

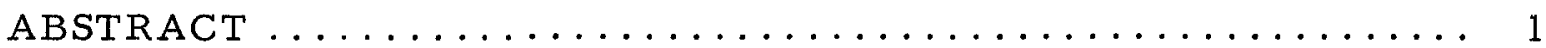

LIST OF ILLUSTRATIONS $\ldots \ldots \ldots \ldots \ldots \ldots \ldots \ldots \ldots \ldots \ldots \ldots \ldots$

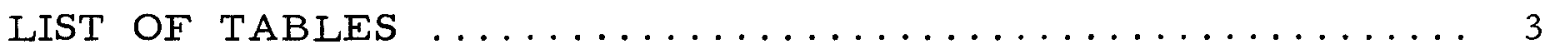

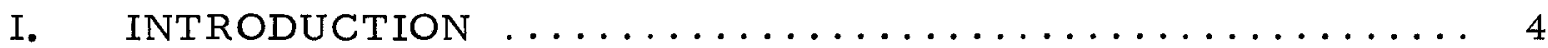

II. ACOUSTIC CONSIDERATIONS FOR UNDER SODIUM

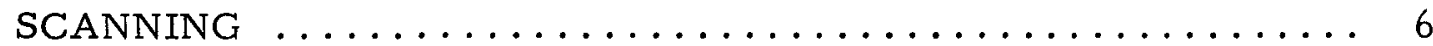

A. Basic Acoustic Considerations ................. 6

1. Velocity of Sound and Characteristic Acoustic

Impedance of Liquid Sodium and Other Compatible

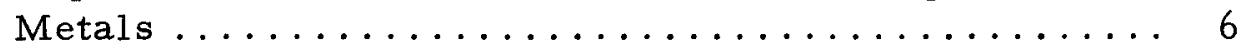

2. Reflection and Scattering in Liquid Sodium ......... 9

B. Ultrasonic Attenuation in Liquid Sodium . . . . . . . . . . 9

C. Properties of Higher Temperature Piezoelectric

Materials ......................... 14

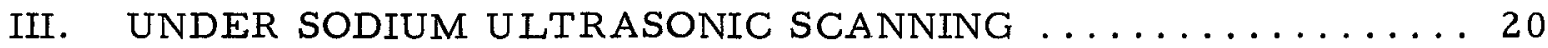

A. Application of Single Transducer .............. 20

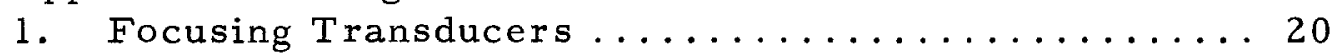

2. Horn-Type Transducers ................. 21

3. Image-Sharpening Circuit and Sharpness of

Acoustic Image ..................... 29

4. Description of Complete Systems ............ 32

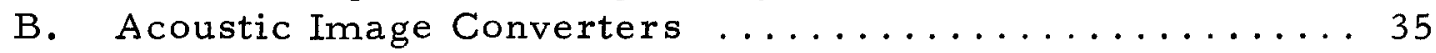

1. Review of Acoustic Image Converters ........... 35

2. Sensitivity of Acoustic Image Converters . . . . . . . . 37

3. Considerations for Operation in Liquid Sodium ...... 38

IV. APPLICATIONS FOR SCANNER SYSTEMS ...........4 4

A. Applications for A-Scan and B-Scan Displays ......... 41

1. Locating Objects ..................... 41

2. Distance and Thickness Measurements .......... 41

3. Controlling the Movement of an Object ........... 41

B. Applications for C-Scan and the Acoustic Image Converter. 42

1. Identifying Subassemblies ................ 42

2. Obtaining Images of Objects ................ 42

3. Defining the Orientation of Objects ............. 42

4. Under Sodium Nondestructive Testing. ............. 44

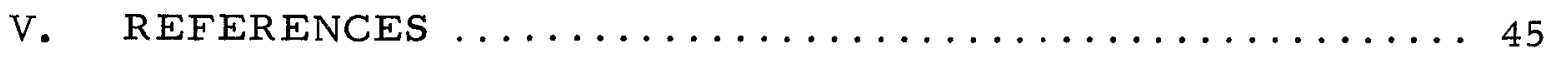




\section{LIST OF ILLUSTRATIONS}

Figure

Scattering Distribution of Steel Cylinders, Decibels ...... 10

Under Sodium Scanner Test Apparatus ............. 12

Absorption Coefficient of Liquid Sodium . . . . . . . . . . 13

Intensity Attenuation in Liquid Sodium . . . . . . . . . 15

Temperature Variation of $\mathrm{d}_{31}$ for Prestabilized

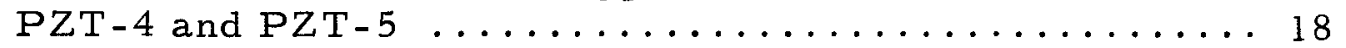

Typical Signal Obtained from Transducers Operating in Liquid Sodium ........................ 18

Horn-Type Transducers and Transducer Assembly ..... 22

Radiation Patterns of Horn-Type Transducer.......... 25

Beam Width as a Function of Angles of Wedge-Shaped

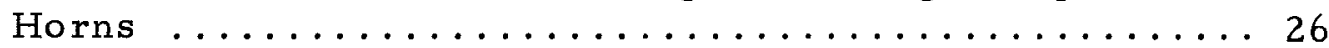

A Typical Reflection Pattern from a Steel Bar......... 30

Reflection from Object Illuminated by Moving

Radiation Beam ....................... $30^{-}$

Illustration and Block Diagram of Image-Sharpening

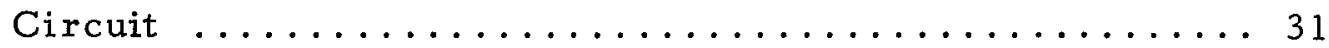

Echoes from Brass Concave Surface .............. 33

Functional Diagram of Ultrasonic Scanner ........... 34

Typical Acoustic Image Conversion System ........... 36

Acoustic Image Converter for Operation in Liquid Sodium. . 40

Identification Marks on Subassemblies ............ 43

\section{LIST OF TABLES}

Table

I. Velocity of Sound and Characteristic Acoustic

Impedance of Liquid Sodium . . . . . . . . . . . 7

II. Characteristic Acoustic Impedance and Index of Refraction of Several Metals in Liquid Sodium .............. 8

III. Properties of Higher Temperature Piezoelectric Materials 16

IV. Temperature Variation of Volume Resistivity of Several Piezoelectric Ceramics ...................... 19

V. Intensity Distribution of a Horn-Type Transducer . . . . . 27

VI. Comparison of Radiation Patterns for Different Throat Apertures of a Wedge-Shaped Horn ............ 28 


\section{INTRODUCTION}

In liquid-metal-cooled nuclear reactors, when performing maintenance, locating and identifying subassemblies, locating foreign objects, and even during routine plant operation, the ability to optically observe an object or particular areas in the coolant system is highly desirable. However, since liquid metals such as sodium are opaque, direct optical observation, except by displacement of the sodium, is not possible; indirect methods, therefore, must be used. The utilization of ultrasonics appear to offer capabilities of viewing in opaque media where satisfactory resolution can be achieved. Since ultrasonic sound energy can be reflected, scattered, or obsorbed by an object, the object can be located by means of a directional ultrasonic beam. The image of objects can be obtained through the mechanical scanning of an ultrasonic beam scanning device or by an electronic acoustic image conversion system which uses an electron beam sweep.

The successful development of an ultrasonic beam orientation to locate an object in liquid sodium has been made possible by the recent determination of ultrasonic attenuation in liquid sodium and the development of a transducer which operates at high temperatures. With the determination of the low absorption coefficient for sound waves transmitting through liquid sodium and the development of a high-operating-temperature transducer, the concepts for under sodium, ultrasonic, scanning systems were established by applying fundamental acoustic considerations.

For the control of the ultrasonic radiation pattern, directional, horntype transducers have been investigated experimentally. The results indicate that the minor lobes of the beam pattern generated by a piezoelectric disk can be well suppressed. The use of acoustic lens systems to direct and concentrate sound waves into a focal zone at relatively short distances provides satisfactory resolutions in nondestructive testing. This principle will be applied to scanning systems for identifying objects at close range. The developement of single-narrow-beam transducers which operate in high temperature liquid sodium and the improvement of the resolving power of the acoustic image or shadowgraph for various distances is a major step forward from the use of a mechanical scanning device.

A different approach to acoustic scanning in liquid metals is the utilization of electronic acoustic methods. These systems have already been used in many practical applications, with room temperature water as the transmission medium. A review of a number of electronic acoustic imaging systems is given here, and the limitations to the maximum attainable sensitivity in the acoustic image converter (AIC) are discussed; to a lesser extent, other design considerations for AIC operating in liquid metals are also discussed. 
A review of some typical applications of ultrasonic scanning systems in liquid-metal-cooled nuclear reactors is presented in the final section of this report. 


\section{ACOUSTIC CONSIDERATIONS FOR UNDER SODIUM SCANNING}

\section{A. BASIC ACOUSTIC CONSIDERATIONS}

1. Velocity of Sound and Characteristic Acoustic Impedance of Liquid Sodium and Other Compatible Metals

When using either a pulse technique or a frequency modulating method to measure the range of an object or the thickness of a plate with ultrasonics, the velocity of sound in the medium must be known. Kleppa and Pochapsky have made independent measurements of the acoustic velocity of sound in liquid sodium.1,2 For the temperature range from the melting point of sodium to $521 \mathrm{~F}$, an empirical formula, accurate to about $\pm 0.2 \%$, is 3

where

$$
c=257725-52.4 \mathrm{~T}
$$

$$
\begin{aligned}
& \mathrm{c}=\text { acoustic velocity in } \mathrm{cm} / \mathrm{sec} \\
& \mathrm{T}=\text { temperature }, \mathrm{C}
\end{aligned}
$$

Calculated values of sound velocity in liquid sodium at $5 \mathrm{C}$ intervals are given in Table I. From Equation (1), a correction for thickness measurements at various temperatures can be calculated. It follows that

$$
\frac{\partial \mathrm{D}}{\partial T}=-5.24 \times 10^{-5} \mathrm{t}\left(\mathrm{cm} /{ }^{\circ} \mathrm{C}\right)
$$

where

$$
\begin{aligned}
& D=\text { thickness in } \mathrm{cm} \\
& \mathrm{t}=\text { time in microseconds }
\end{aligned}
$$

The characteristic acoustic impedance $Z_{O}$ of a medium is an important parameter in acoustic impedance matching or mismatching on the problems of transmission, reflection, and refraction. The following expression is an adequate representation of the density $\rho$ of liquid sodium, valid to about $\pm 0.0020:^{3}$

$$
\rho=0.9490-0.000223 \mathrm{~T}-0.0000000175 \mathrm{~T}^{2}\left(\mathrm{gm} / \mathrm{cm}^{3}\right)
$$

then

$$
\begin{gathered}
\frac{d Z_{o}}{d T}=\frac{d}{d T} \quad(\rho c)=-107.200275+0.014350025 \mathrm{~T}+0.000002751 \mathrm{~T}^{2} \\
\left(\mathrm{gm} / \mathrm{cm}^{2}-\sec ^{\circ} \mathrm{C}\right)
\end{gathered}
$$

Table I gives the characteristic acoustic impedances of liquid sodium in the temperature range from $97.83 \mathrm{C}$ to $310 \mathrm{C}$. The characteristic acoustic impedances of several other metals which are compatible with liquid sodium are listed in Table II. 
TABLE I

VELOCITY OF SOUND AND CHARACTERISTIC ACOUSTIC IMPEDANCE OF LIQUID SODIUM

\begin{tabular}{c} 
Temperature, \\
C \\
\hline 97.83 \\
100 \\
105 \\
110 \\
115 \\
120 \\
125 \\
130 \\
135 \\
140 \\
145 \\
150 \\
155 \\
160 \\
165 \\
170 \\
175 \\
180 \\
185 \\
190 \\
195 \\
200 \\
205 \\
210 \\
215 \\
220 \\
225 \\
230 \\
235 \\
240 \\
245 \\
250 \\
255 \\
260 \\
265 \\
270 \\
275 \\
280 \\
285 \\
290 \\
295 \\
300 \\
305 \\
310 \\
\end{tabular}

Velocity of Sound $x$ 10-5, $\mathrm{cm} / \mathrm{sec}$

2.526

2. 525

2.522

2. 520

2. 517

2.514

2.512

2. 509

2. 507

2. 504

2. 501

2. 499

2. 496

2. 493

2. 491

2. 488

2. 486

2. 483

2. 480

2. 478

2. 475

2. 472

2. 470

2. 467

2. 465

2. 462

2. 459

2. 457

2. 454

2. 451

2. 449

2. 446

2. 444

2. 441

2. 438

2. 436

2. 433

2. 431

2. 428

2. 425

2. 423

2. 420

2. 417

2. 415
Characteristic Acoustic Impedance $\times 10^{-6}$, $\mathrm{gm} / \mathrm{cm}^{2}-\mathrm{sec}$

0.2342

0.2339

0.2334

0.2329

0.2323

0.2318

0.2313

0.2308

0.2303

0.2297

0.2292

0.2287

0.2281

0.2276

0.2271

0.2266

0.2261

0.2255

0.2250

0.2245

0.2240

0.2234

0.2229

0.2224

0.2219

0.2214

0.2208

0.2203

0.2198

0.2192

0.2188

0.2182

0.2178

0.2172

0.2167

0.2162

0.2157

0.2152

0.2146

0.2141

0.2136

0.2131

0.2126

0.2121 
CHARACTERISTIC ACOUSTIC IMPEDANCE AND INDEX OF REFRACTION

OF SEVERAL METALS IN LIQUID SODIUM

\begin{tabular}{lccc} 
Sodium & 2.420 & 0.2131 & 1.000 \\
\hline Beryllium & 12.890 & 2.4100 & 5.326 \\
Cobalt & 4.724 & 4.3040 & 1.952 \\
Nickel & 4.785 & 4.9500 & 1.977 \\
Steel & 5.790 & 4.5600 & 2.393 \\
Tungsten & 5.460 & 10.4200 & 2.256
\end{tabular}

Characteristic Acoustic Impedance $\times 10^{-6}$, $\mathrm{gm} / \mathrm{cm}^{2}-\mathrm{sec}$

Index of Refraction

Material $\mathrm{cm} / \mathrm{sec}$

0.2131 in Liquid Sodium
1.000

2.420

0.4200 


\section{Reflection and Scattering in Liquid Sodium}

If the boundary of an acoustic field has dimensions which are large compared with wavelength, one obtains the simple laws of reflection and refraction. Similarly, if the obstacle is large compared with wavelength, a shadow zone is formed. In some cases where the Huyghens sources are confined to finite regions, diffraction phenomena generally results. In general, the total disturbance of the sound wave by the obstacle is obtained by a particular set of Huyghens waves. The distribution of these Huyghens waves must be such that their radiation pattern produces all the field characteristics (reflection, diffraction, and shadow formation) by interference with the undisturbed sound wave. This interfering radiation pattern of the obstacle is called the "scattered wave".

Whenever plane waves in an unbounded fluid medium are incident at right angles upon the surface of an extended solid body, the ratio of the reflected sound energy to the incident sound energy is

$$
\beta_{r}=\left(\frac{r_{12}-1}{r_{12}+1}\right)^{2}
$$

where

$$
\begin{aligned}
\beta_{r}= & \text { the sound reflection coefficient } \\
r_{12}= & \text { the ratio of the characteristic acoustic impedance of the solid } \\
& \text { body to the characteristic acoustic impedance of the fluid. }
\end{aligned}
$$

For the case of liquid sodium and stainless steel at $600 \mathrm{~F}$ where $\mathrm{r}_{12}$ is approximately $21.6, \beta_{r}$ is approximately $83 \%$.

For the purpose of demonstrating the scattering phenomena, some experimental results on steel cylinders obtained at a frequency of $1 \mathrm{Mc} / \mathrm{sec}$ are presented in Figure 1.4 The proper selection of wavelength for different object dimensions depends on the scattering effect which will be utilized in the ultrasonic scanning system.

\section{B. ULTRASONIC ATTENUATION IN LIQUID SODIUM}

Whenever sound waves propagate through a fluid medium, there is a loss of acoustic energy. The sources of this loss may be divided into two general categories: (1) those associated with conditions at the boundaries of the medium and (2) those due to the dissipation of acoustic energy in the medium itself. The first type of loss is of particular significance when the volume of the fluid is small in comparison with the area of the boundary walls. In an unbounded medium, the intensity of a plane wave decreases in accordance with the equation 5

$$
I=I_{0} e^{-2 a x}
$$



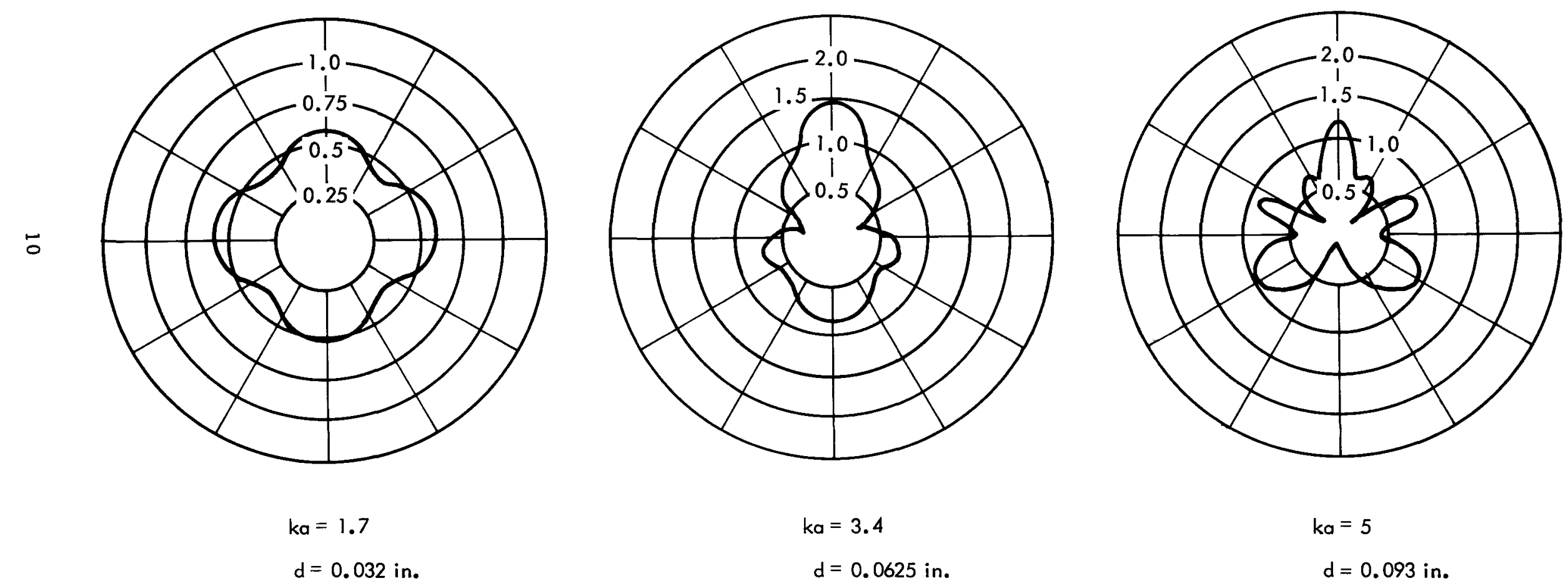

$$
\begin{aligned}
k a & =3.4 \\
d & =0.0625 \mathrm{in} .
\end{aligned}
$$

$$
\begin{aligned}
k a & =5 \\
d & =0.093 \mathrm{in} .
\end{aligned}
$$

Note: The diameter of cylinders is $d=2 a$. The wave number $k$ refers to the surrounding liquid.

FIG. 1 SCATTERING DISTRIBUTION OF STEEL CYLINDERS, DECIBELS 
where the intensity $I_{O}$ falls to a value $I$ after traveling a distance $x$, and $a$ is the intensity absorption coefficient of a plane wave. The common explanation of the second type of loss, the absorption of ultrasonic energy in the medium itself, is that it is due to the shear viscosity $\eta_{S}$, the bulk viscosity $\eta_{B}$, and the thermal conductivity $K$ of the fluid. The theoretical expression for the absorption coefficient is $6,7,8$

$$
a=\frac{2 \pi^{2} f^{2}}{\rho c^{3}}\left(\frac{4}{3} \eta_{s}+\eta_{B}+\frac{\gamma-1}{c_{p}} K\right)
$$

whe re

$$
\begin{aligned}
& f=\text { frequency of the wave } \\
& \rho=\text { mean density of the medium } \\
& c=\text { velocity of sound } \\
& \gamma=c_{p} / c_{v} \\
& c_{p}=\text { specific heat at constant pressure } \\
& c_{v}=\text { specific heat at constant volume }
\end{aligned}
$$

Since $\eta_{B}$ is an unknown parameter, the measurement of the absorption coefficient of liquid sodium is necessary for the development of ultrasonic scanning devices; Figure 2 shows the apparatus for measurement of the absorption coefficient. By simply omitting a value for the bulk viscosity $\eta_{B}$ the remainder of the theoretical expression for the absorption coefficient may be used to calculate the so-called classical absorption coefficient.

From equation (6), the absorption coefficient $a$ and the frequency $f$ have the relation

$$
\frac{a}{f^{2}}=\frac{2 \pi^{2}}{\rho c^{3}}\left(\frac{4}{3} \eta_{s}+\eta_{B}+\frac{\gamma-1}{c_{p}} K\right)
$$

then at constant temperature

$$
\frac{a}{f^{2}}=\text { constant }
$$

For almost all liquids, this relation is also satisfied experimentally over a wide range of frequencies. Figure 3, ob tained from experimental results 9 and equation (8) show the absorption coefficients of liquid sodium as a function of frequencies at various temperatures. The experimental values of $a / f^{2}$ are almost a linear function of the temperatures.

In $600 \mathrm{~F}$ liquid sodium

$$
\frac{a}{f^{2}}=21 \times 10^{-17} \mathrm{sec}^{2} \mathrm{~cm}^{-1}
$$




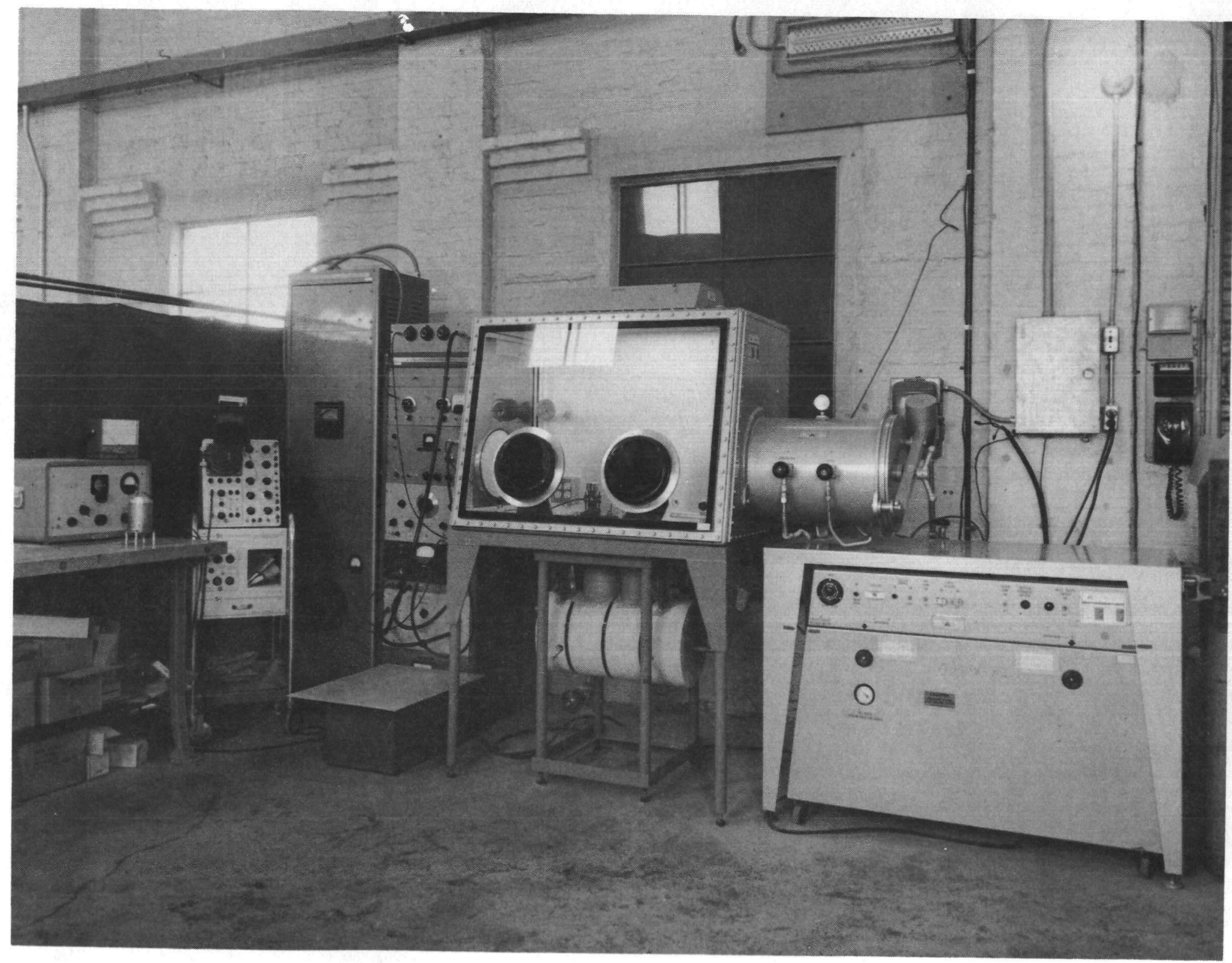

FIG. 2 UNDER SODIUM SCANNER TEST APPARATUS 


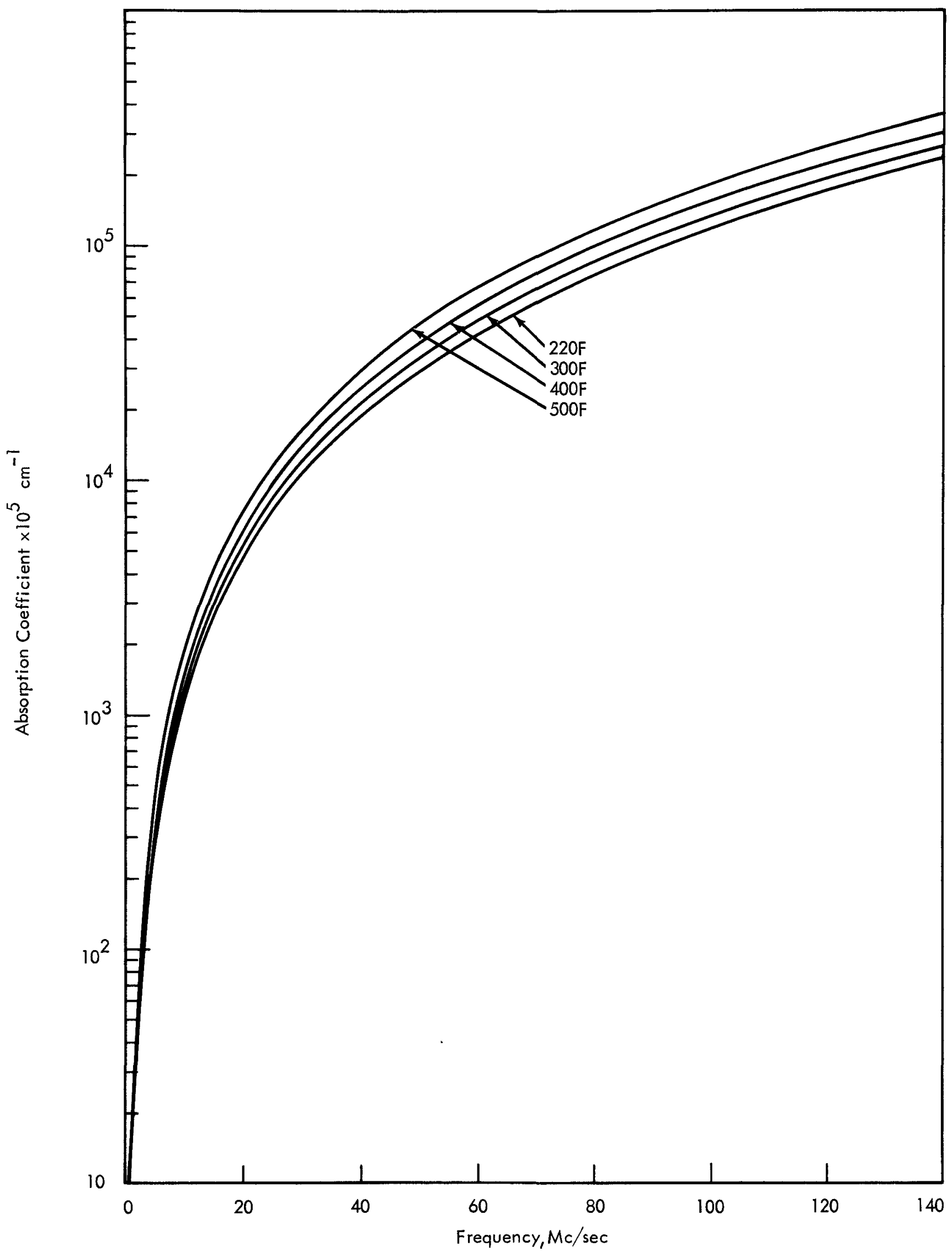

FIG. 3 ABSORPTION COEFFICIENT OF LIQUID SODIUM

13 
Comparing this value with that of water at $59 \mathrm{~F} 10$

$$
\frac{a}{f^{2}}=24 \times 10^{-17} \sec ^{2} \mathrm{~cm}^{-1}
$$

Obviously, the ultrasonic attenuation in liquid sodium is less than that in water.

Using the value given in (9) and obtaining the $a^{\prime}$ s for various frequencies, the relative intensities can be calculated explicitly at various distances by equation (5). The results of these calculations are plotted in Figure 4, which gives a picture of the necessary frequency for different work distances. If the work distance is less than $10 \mathrm{ft}$, the problem of attenuation can be ignored at frequencies below $1 \mathrm{Mc} / \mathrm{sec}$. Frequencies up to $10 \mathrm{Mc} / \mathrm{sec}$ or $30 \mathrm{Mc} / \mathrm{sec}$ can be used for work distances within a few feet or a few inches, respectively. Above $50 \mathrm{Mc} / \mathrm{sec}$, ultrasonics can only work at distances less than one inch.

\section{PROPERTIES OF HIGHER TEMPERATURE PIEZOELECTRIC MATERIALS}

The required operating temperature of a transducer in an ultrasonic scanning system for liquid metal cooled reactors is about $600 \mathrm{~F}$. Several piezoelectric materials having higher curie points, which are the limiting temperature of the piezoelectric effect, will be introduced in this section. Table III lists the piezoelectric properties of these materials at room temperature $(77 \mathrm{~F})$. The definition of most constants in the table can be derived from the static piezoelectric equations. For practical purposes the effects of magnetic fields and heat interchange may be ignored when considering piezoelectric materials; then the piezoelectric equations can be expressed in the following matrix form: 11

where

$$
\begin{aligned}
& S=s E_{T}+d_{t} E \\
& D=, d T+\epsilon T_{E}
\end{aligned}
$$

$\mathbf{S}=$ elastic strain with components $S_{\mathbf{i}}$

$\mathrm{T}=$ elastic stress with components $\mathrm{T}_{\mathbf{j}}$

$E=$ electric field with components $E_{k}$

$\mathrm{D}=$ electric displacement with components $D_{\mathrm{m}}$

$\mathbf{s}^{E}=$ elastic compliance with elements $\mathbf{s} \underset{i j}{E}$

$\mathrm{d}=$ piezoelectric constant with elements $\mathrm{d}_{\mathrm{mj}}$

$\epsilon^{\mathrm{T}}=$ dielectric constant with elements $\epsilon \underset{\mathrm{mk}}{\mathrm{T}}$

$d_{t}=$ transposed matrix of $d$-matrix

and

$$
\begin{aligned}
\mathrm{i}, \mathrm{j} & =1 \text { to } 6 \\
\mathrm{~m}, \mathrm{k} & =1 \text { to } 3
\end{aligned}
$$




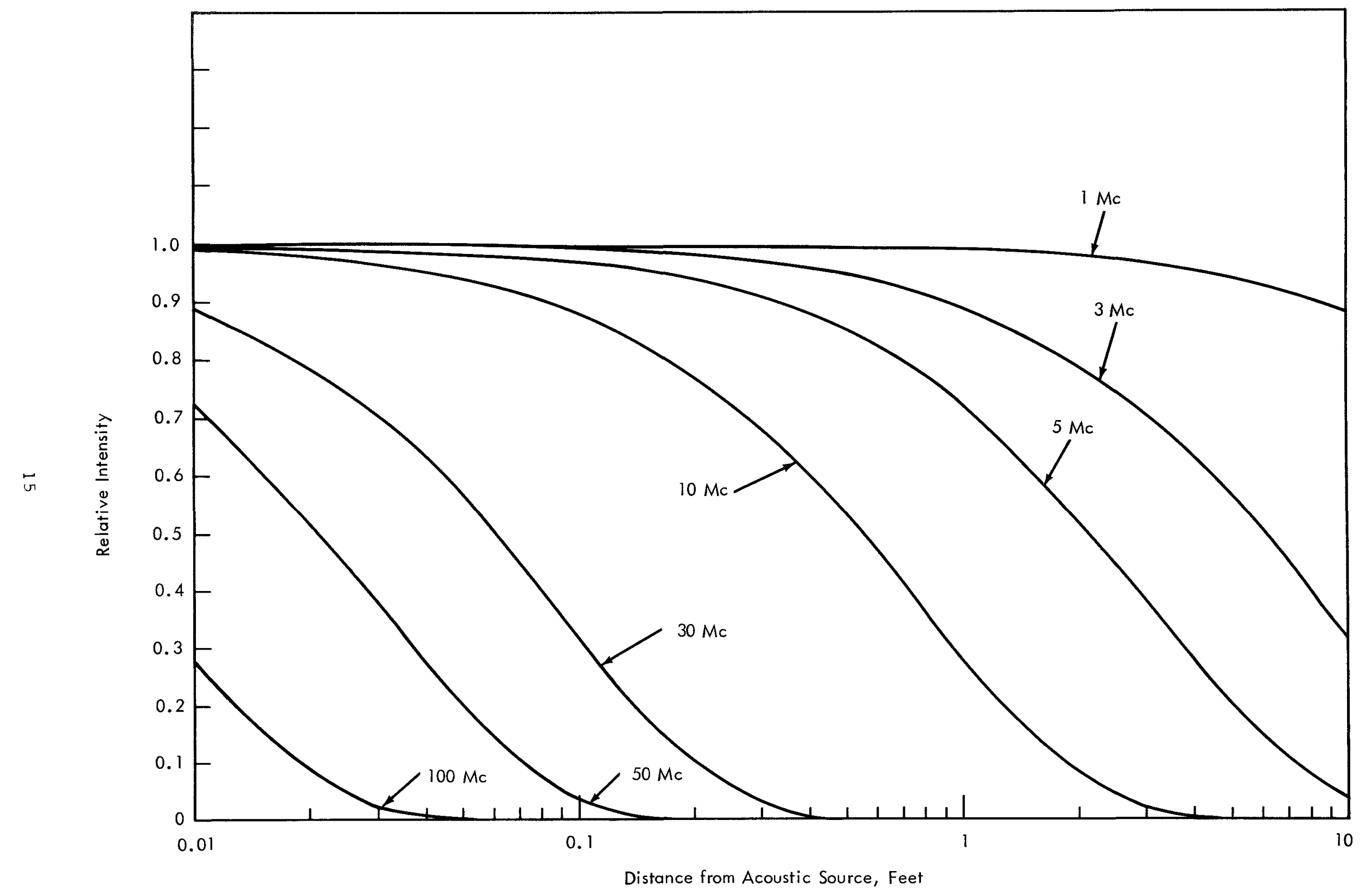

FIG. 4 INTENSITY ATTENUATION IN LIQUID SODIUM 
TABLE III

\section{PROPERTIES OF HIGHER TEMPERATURE PIEZOELECTRIC MATERIALS}

\begin{tabular}{|c|c|c|c|c|c|c|}
\hline Quantity & $\mathrm{PZT}-4$ a & PZT-5 a & $\mathrm{PbZr}_{0.54} \mathrm{Ti}_{0.46} \mathrm{O}_{3}^{\mathrm{b}}$ & $\mathrm{PbNb}_{2} \mathrm{O}_{6} \mathrm{c}$ & $\mathrm{Na}_{0.5} \mathrm{~K}_{0.5} \mathrm{NbO}_{3}{ }^{\mathrm{d}}$ & $\mathrm{SiO}_{2}$ \\
\hline $\mathrm{k}_{31}$ & $(-) 0.334$ & (-) 0.344 & $(-) 0.280$ & $(-) 0.045$ & (-) $0.22,0.27$ & \\
\hline $\mathrm{k}_{33}$ & 0.70 & 0.705 & 0.626 & 0.38 & $0.51,0.53$ & \\
\hline $\mathrm{k}_{15}=\mathrm{k}_{\mathrm{il}}$ & 0.71 & 0.685 & 0.701 & & & \\
\hline $\mathrm{k}_{\mathrm{i} 3}$ & 0.715 & 0.715 & 0.650 & & & \\
\hline$\epsilon_{33}^{\mathrm{T}} / \epsilon_{\mathrm{o}}$ & 1300 & 1700 & 450 & 225 & 290,420 & 4.52 \\
\hline${ }_{\epsilon}^{\epsilon}{ }_{11}^{T}{ }^{\epsilon} 0$ & 1475 & 1730 & 990 & & & 4.68 \\
\hline \multicolumn{6}{|l|}{$\mathrm{d}_{11}, 10^{-12} \mathrm{C} / \mathrm{N}$} & 2.31 \\
\hline$d_{14}$ & & & & & & 0.727 \\
\hline $\mathrm{d}_{33}$ & 289 & 374 & 152 & 85 & 80,160 & \\
\hline $\mathrm{d}_{31}$ & -123 & -171 & -60.2 & $\sim-9$ & $-32,-49$ & \\
\hline$d_{15}$ & 496 & 584 & 440 & & & \\
\hline $\mathrm{s}_{11}^{\mathrm{E}}, 10^{-12} \mathrm{~m}^{2} / \mathrm{N}$ & 12.3 & 16.4 & 11.6 & & $9.6,8.7$ & 12.77 \\
\hline$s_{33}^{E}$ & 15.5 & 18.8 & 14.8 & 25.4 & & 9.60 \\
\hline $\begin{array}{c}\mathrm{E} \\
\mathrm{s} 12\end{array}$ & -4.05 & -5.74 & -3.33 & & & -1.79 \\
\hline $\mathrm{s}_{13}^{\mathrm{E}}$ & $-5,31$ & -7.22 & -4.97 & & & -1.22 \\
\hline $\mathrm{s}_{44}^{\mathrm{E}}$ & 39.0 & 47.5 & 45.0 & & & 20.04 \\
\hline $\mathrm{s}_{14}^{\mathrm{E}}$ & & & & & & 4.50 \\
\hline$s_{66}$ & 32.7 & 44.3 & 29.9 & & & 29.12 \\
\hline $\begin{array}{c}Q_{c} \text { (elastic } \\
\text { quality factor) }\end{array}$ & 500 & 75 & 680 & 11 & 130,240 & \\
\hline $\begin{array}{l}\rho \text { (density) } \\
10^{3} \mathrm{Kg} / \mathrm{m}^{3}\end{array}$ & 7.5 & 7.75 & 7.62 & 6.0 & $4.25,4.46$ & 2649 \\
\hline Curie point & $328 \mathrm{C}$ & $365 \mathrm{C}$ & $370 \mathrm{C}$ & $570 \mathrm{C}$ & $420 \mathrm{C}$ & $576 \mathrm{C}$ \\
\hline $\begin{array}{l}\text { Volume Resis- } \\
\text { tivity (ohm m) }\end{array}$ & $>10^{10}$ & $>10^{11}$ & $>10^{10}$ & $7 \times 10^{8}$ & $\sim 10^{10}$ & \\
\hline \multicolumn{7}{|c|}{$\begin{array}{l}\text { a Trademark, Clevite Corporation, one of the lead zirconate-titanates } \\
\text { b Berlincourt et al. } 12 \\
\text { c General Electric } \mathrm{Co}_{3} \\
\text { d C. S. Brown et al. } 13\end{array}$} \\
\hline & $\frac{1}{\times 9 \times 10^{9}}$ & $/ \mathrm{m}$ & & & & \\
\hline
\end{tabular}


An important property of piezoelectric materials is their piezoelectric coupling factors. The piezoelectric coupling factor $k$ may be defined as the ratio of the mutual elastic and dielectric energy density to the geometric mean of the elastic and dielectric self-energy densities.

Figure 5 shows the variation with temperature of the piezoelectric constant $d_{31}$ for prestabilized ceramic PZT -4 and PZT -5 . Table IV lists the data for the se and $\mathrm{PbZr} 0.54 \mathrm{Ti} 0.46 \mathrm{O}_{3}$ in tabular form.

With high electric input, the relationships between strain and electric fields and between displacement and electric field become nonlinear. Nonlinearity of the strain-field relationship produces harmonic distortion of the acoustic output; the increase in dielectric loss resulting from nonlinearities in the displacement-field relationship lowers electroacoustic efficiency and generates heat. In general, strain remains a linear function of alternating electric field at considerably higher electric fields than does dielectric displacement.

Piezoelectric ceramics are presently used in most high-power acoustic radiators. Crystals which were formerly used have been displaced largely because of severe limitations. Quartz, for instance, is superior to the ceramics with respect to tensile strength and severe ambient conditions, but its low piezoelectric coupling severely limits bandwidth.

Qualitative testing of piezoelectric materials 7 indicates that PZT-5 works satisfactorily and relatively better at $600 \mathrm{~F}$ than quartz and lead metaniobate. The electrical resistivity and piezoelectric activity of lead metaniobate decrease above $300 \mathrm{~F}$, and the quartz shows a decreasing piezoelectric activity above $500 \mathrm{~F}$. A signal typical of one obtained from the piezoelectric materials that were tested in $600 \mathrm{~F}$ sodium is shown in Figure 6.

Recently, a new piezoelectric ceramic, lithium metaniobate ( $\mathrm{LiNbO}$ ), having a curie temperature of $1210 \mathrm{C} \pm 10 \mathrm{C}$, was developed by the Bell Telephone Laboratories. 


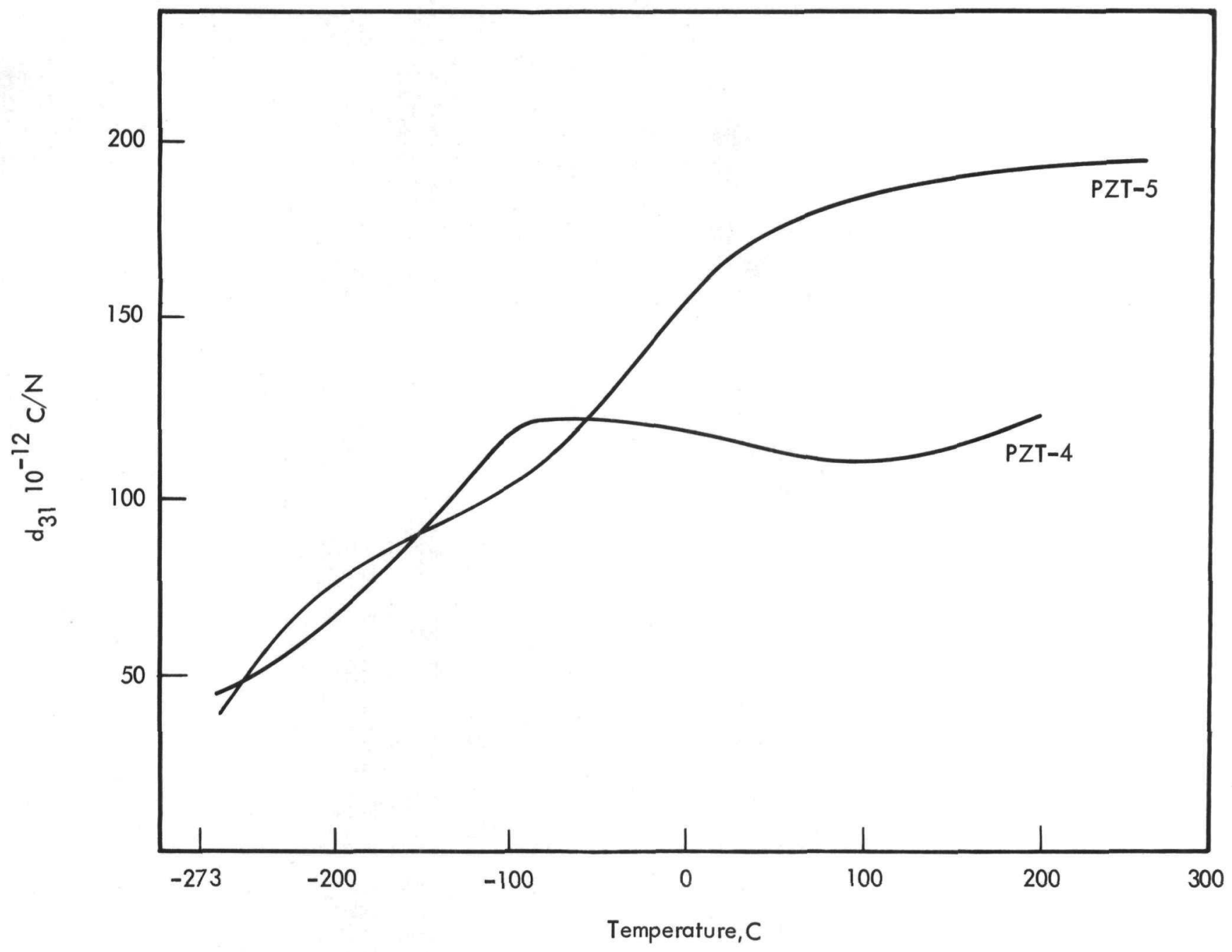

FIG. 5 TEMPERATURE VARIATION OF d 31 FOR PRESTABILIZED PZT-4 AND PZT-5

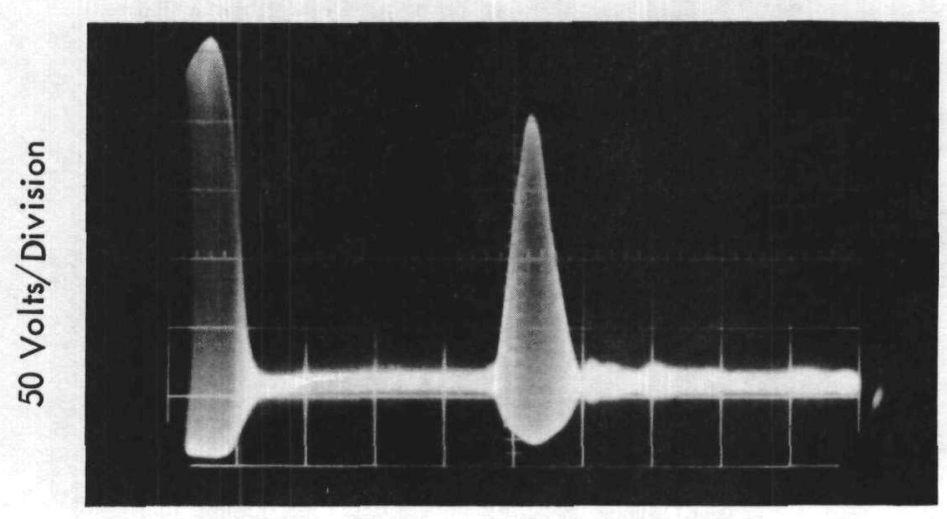

$20 \mathrm{Microsecond/Division}$

FIG. 6 TYPICAL SIGNAL OBTAINED FROM TRANSDUCERS OPERATING IN LIQUID SODIUM 
TABLE IV

TEMPERATURE VARIATION OF VOLUME RESISTIVITY OF SEVERAL PIEZOELECTRIC CERAMICS

\section{(ohm-meters)}

\begin{tabular}{|c|c|c|c|}
\hline Temperature, $\mathrm{C}$ & $\mathrm{PZT}-4$ & $\mathrm{PZT}-5$ & $\mathrm{PbZr}_{0.54} \mathrm{Ti}_{0.46^{\mathrm{O}_{3}}}$ \\
\hline 25 & $>10^{10}$ & $>10^{11}$ & $>10^{10}$ \\
\hline 100 & $10^{8.5}$ & $10^{11}$ & $10^{8.5}$ \\
\hline 200 & $10^{6.5}$ & $10^{9}$ & $10^{6.5}$ \\
\hline
\end{tabular}




\section{UNDER SODIUM ULTRASONIC SCANNING}

\section{A. APPLICATION OF SINGLE TRANSDUCER}

1. Focusing Transducers

To obtain high resolution of a shadowgraph in a single transducer scanning device, the object should be illuminated with a very fine spot of ultrasonic energy. Focusing transducers with ultrasonic lenses, which have been used successfully to produce a fine focusing point in water, may be used for this purpose. For a simple spherical lens having a small aperture the radius of curvature of the concave face is 14

$$
r=f\left(\frac{n-1}{n}\right)
$$

where

$$
\begin{aligned}
& \mathbf{f}=\text { the focal length } \\
& \mathbf{n}=\text { the index of refraction }
\end{aligned}
$$

Table II gives the index of refraction of several metals which are compatible with liquid sodium. Since the radius of the circular cross section of the beam in the focal plane is proportional to the radius of curvature of the concave face of the lens, the smaller the index of refraction the smaller will be the circular cross section of the beam in the focal plane at the same focal length. The axial pressure at the center of curvature is proportional to 15

$$
\frac{2 \pi}{\lambda}(1-\cos \theta)
$$

where

$\lambda=$ wavelength of sound in fluid medium

$\theta=$ half-angle subtended by lens (from the center of curvature)

Thus, if both $f$ and $\theta$ values remain constant, a smaller index of refraction gives less axial pressure gain at the focal point-- a condition which is not conducive to the achievement of a fine focal point. Fortunately, however, the transducers of today can generate sufficient pressure; therefore, the lens can be designed for a smaller circular cross section of the beam at the focal point.

The depth of the focusing field depends on the wavelength and the value of $r \sin \theta$. At certain values of the wavelength and radius of curvature of the lens, more depth can be obtained from a larger value of $\theta$ which will cause greater axial pressure gain at the focal point. 


\section{Horn-Type Transducers}

Since focusing transducers have limitations in work distances, horn-type transducers were investigated experimentally. A 2 Mc transducer, two separate conical horns, and a wedge-shaped horn were designed, fabricated, and tested; previous investigators had conducted experiments with horn-type transducers at frequencies lower than $2 \mathrm{Mc} .16$ The conical and wedge-shaped horns are shown in Figures $7 \mathrm{a}$ and $7 \mathrm{~b}$, respectively, and the assembled transducer and acoustical horns are shown in Figure $7 \mathrm{c}$. Two conical horns fabricated of wood, one 3/4-inch-long and the other 1-3/4-inch-long, were tested. The wedge-shaped horns were fabricated from aluminum plate, and the aluminum was covered with rubber to obtain maximum attenuation of secondary lobes. By means of adjustable brackets the throat aperture $T$, mouth aperture $M$, horn angle $2 a$, and horn separation $S$ could be varied.

Several radiation patterns were measured in water for several conditions for the horns, as shown in Figure 8. The wedge-shaped horn was mounted vertically, and the directivity and secondary lobe attenuation were measured in the horizontal plane. These measurements show that the usefulness of the horns is in focusing the beam patterns. The best pattern was obtained by combining the 1-3/4-inch conical horn and the wedge-shaped horn. This pattern has essentially a single lobe with a $6^{\circ}$ beam width, measured at -3.0 dbs. (See c of Figure 8, and Table V.) The minor lobes of the radiation pattern were suppressed to $40 \mathrm{dbs}$ below the axial response. A separated main lobe was obtained when the $3 / 4$-inch conical horn was used.

Three typical patterns for three different angles of the wedgeshaped horn are shown in $\mathrm{c}, \mathrm{d}$, and e of Figure 8. For a larger angle of the horn, a smoother curve of the lobe is obtained, but the beam width becomes wider. If the angle of the horn is too small, the sharpness for the lobe when using the $1-3 / 4-$ inch horn is very similar to the sharpness when using the 3/4-inch conical horn.

In Figure 9, the beam width measured at $-3.0 \mathrm{dbs}$ is shown as a function of angles a for a horn of constant slant length $L$, where throat aperture $(T)=1 / 8 \mathrm{inch}$, the horn separation $(S)=1 / 16 \mathrm{inch}$, and the length of the conical horn $=3 / 4$ inch. It can be seen that there is a particular value of a which yields a minimum beam width.

Table VI indicates similar data except that constant values were kept for the mouth aperture of the wedge-shaped horn and the horn separation, and the throat aperture of the wedge-shaped horn was varied. The critical value of throat aperture is shown to be $1 / 8$ inch.

The horn separations have also been varied and constant values kept for other factors. Optimum horn separation values are indicated at $1 / 16$ 
WOODEN CONICAL HORN

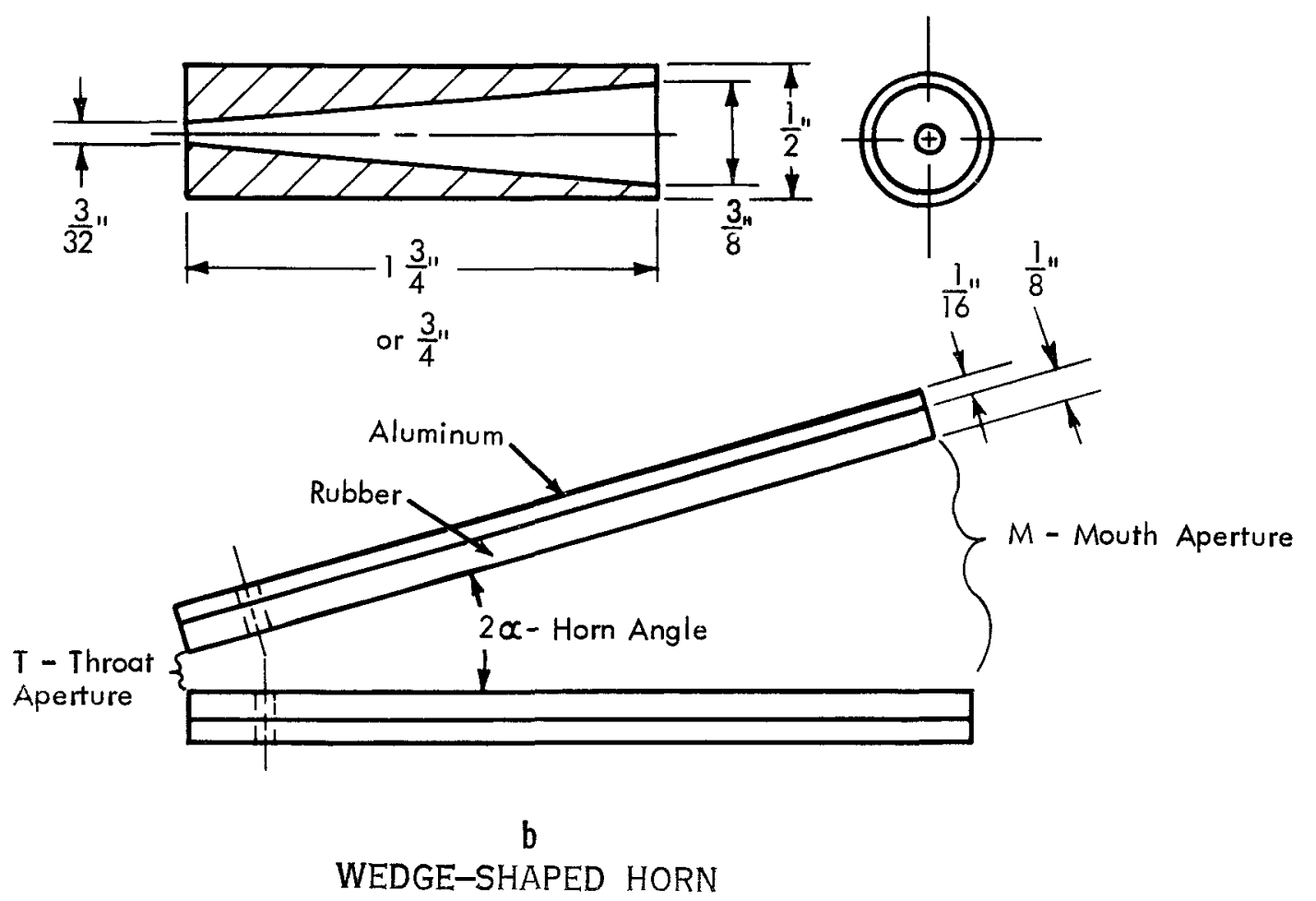

FIG. 7 HORN-TYPE TRANSDUCERS AND TRANSDUCER ASSEMBLY 
b

WED GE-SHAPED HORN

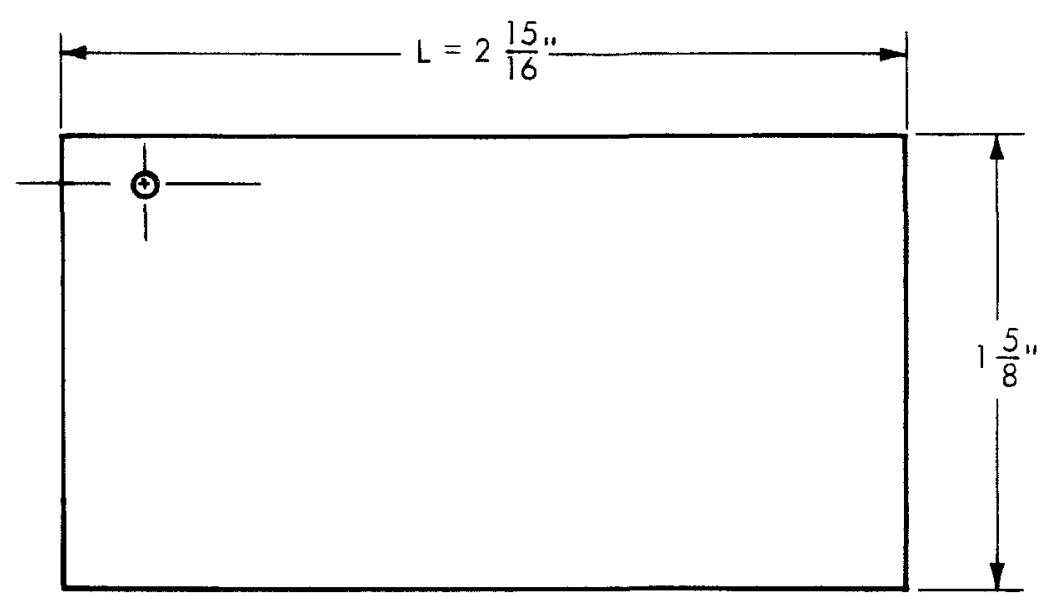

FIG. 7 HORN-TYPE TRANSDUCERS AND TRANSDUCER ASSEMBLY 
c

TRANSDUCER

ASSEMBLY

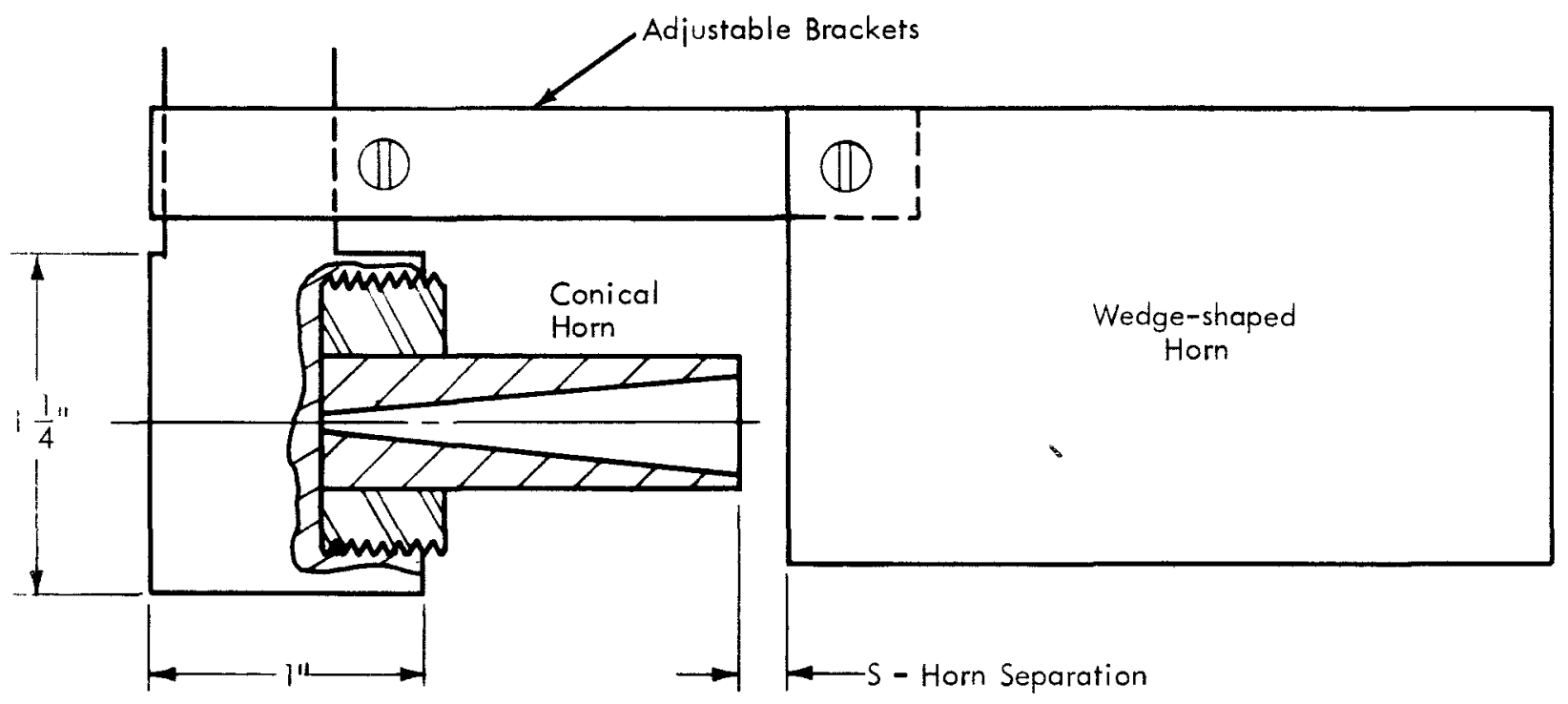

FIG. 7 HORN-TYPE TRANSDUCERS AND TRANSDUCER ASSEMBLY 

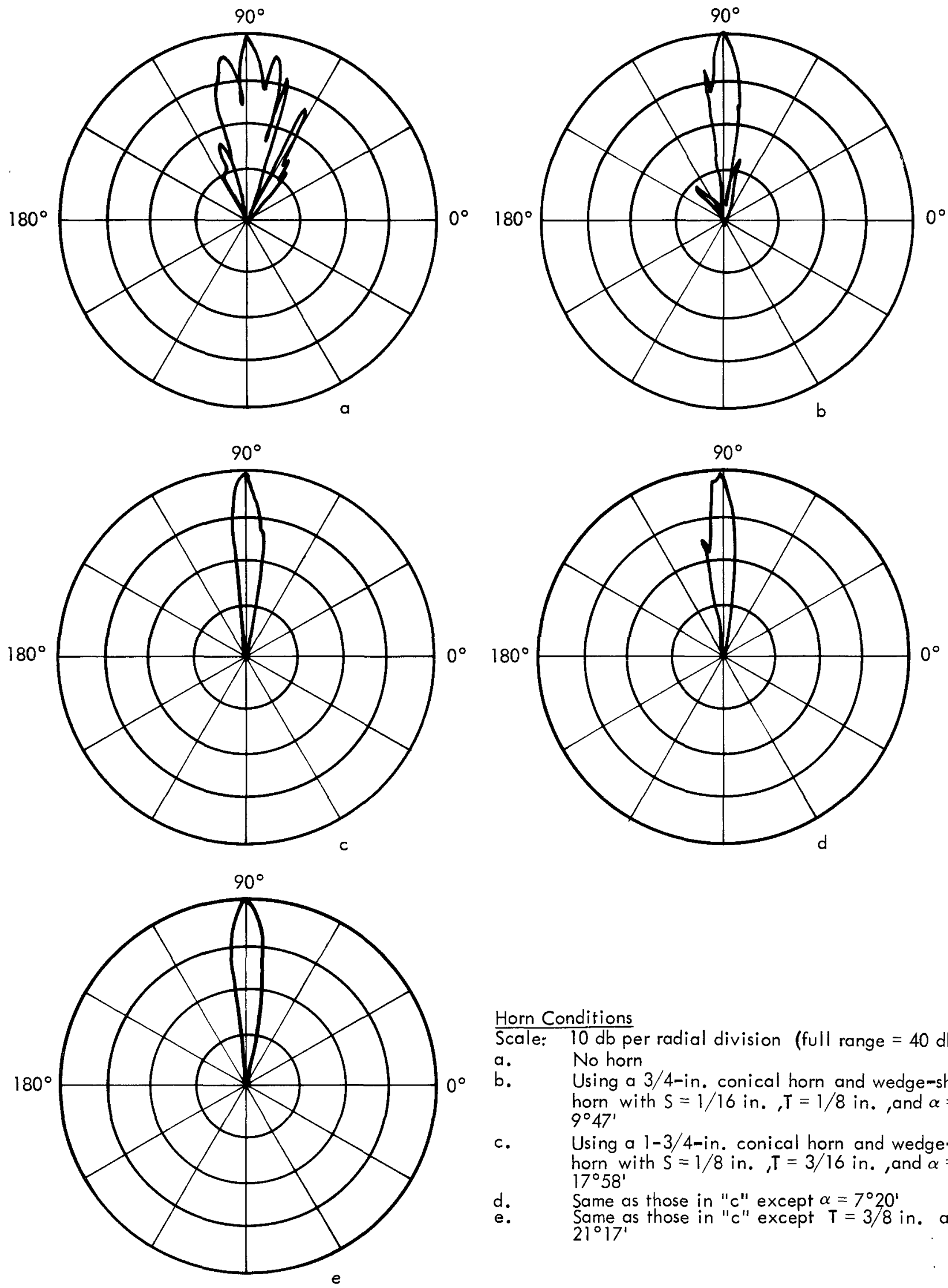

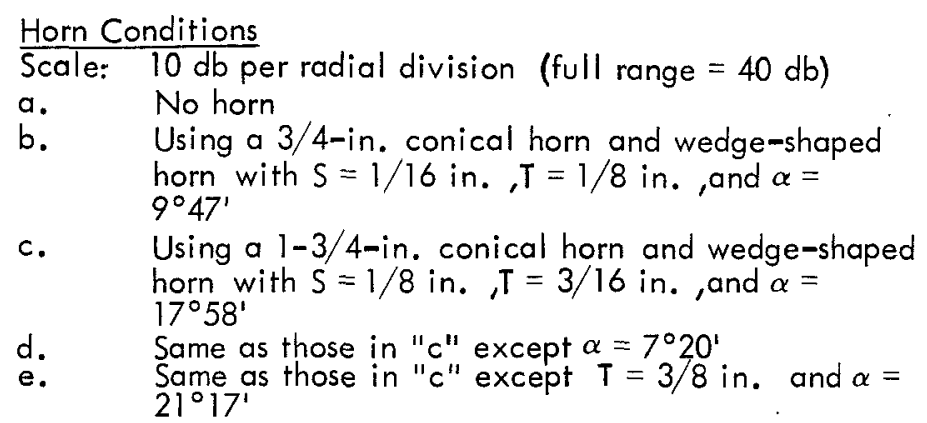

FIG. 8 RADIATION PATTERNS OF HORN-TYPE TRANSDUCER 


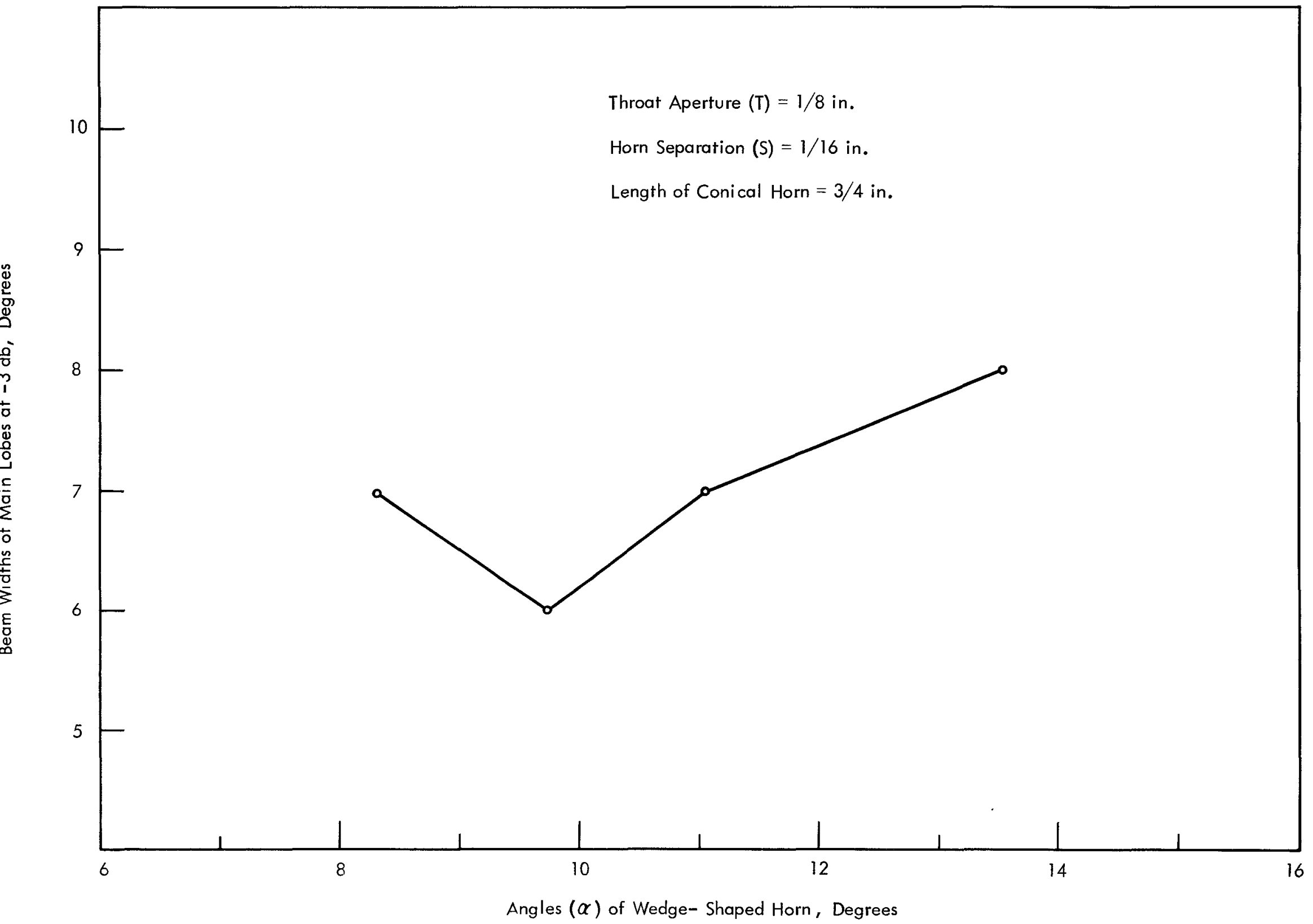

FIG. 9 BEAM WIDTH AS A FUNCTION OF ANGLES OF WEDGE-SHAPED HORNS 


\section{INTENSITY DISTRIBUTION OF A HORN-TYPE TRANSDUCER}

\section{Angles of Transducer, degrees}

81

82

83

84

85

86

87

88

89

90

91

92

93

94

95

96

97

98

\author{
Receiving Signals \\ Peak Voltage in Volts
}

in $\mathrm{db} s$

0

$-\infty$

6

$-23.02$

$18-$

$-13.48-$

$18+$

$-13.48+$

30

$-9.04$

56

$-3.62$

64

$-2.46$

76

$-0.97$

84

$-0.1$

85

0

82

$-0.3$

70

$-1.68$

58

$-3.32$

44

$-5.72$

15

$-15.06$

10

$-18.58$

5

$-24.6$

0

$-\infty$

Note: This data was obtained for the transducer using the combination of a 1-3/4-in. conical horn and a wedge-shaped horn; the separation of the two horns is $1 / 8$ in. 
Throat Aperture of Wedge-Shaped Horn, in.

$1 / 8$

$3 / 16$

$1 / 4$

(n)

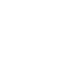

6

9
- 3 db Beam Width, degrees

$-12.04$
$21^{\circ}$ to right
$-28.52$
$33^{\circ}$ to left
$-32.04$

Side Lobes

$\begin{array}{cc}\text { Angles } & \text { Relative } \\ \text { from Center } & \text { Intensities, } d b\end{array}$
$7^{\circ}$ to left
(3) to left

$-32.04$
8
$+2$

$-10^{\circ}$ to left $\quad-18.05$


inch for the 3/4-inch conical horn and $1 / 8$ inch for the $1-3 / 4$-inch conical horn.

From these experimental investigations, it is concluded that factors, such as the throat aperture, the mouth aperture, the dimensions of the conical horn, and the horn separation, are very important for the radiation patterns. The optimum values of these factors were defined with regard to the limited physical size of the horns. During these investigations, the frequency, the throat aperture, and the angle of the conical horn have not been changed, although the beam width of the main lobe might be improved by varying these parameters.

For the case of horns operating in liquid sodium, the structure and materials of the horn should be changed. Fiberfrax cloth as an acoustic absorption material sandwiched between stainless steel plates has been tested in water. The results of this test indicate that the minor lobes can be suppressed with these materials. Using a horn-type transducer, a typical reflection pattern from a steel bar immersed in a tank of water is shown in Figure 10.

In order to determine the acoustic impedance matching between the horn and transducer, the acoustic impedance at the throat of the horn was established. Theoretically, for the case $k a>5$, where $k$ is the wave number in the medium and $a$ is the radius of the mouth of the horn, the characteristic acoustic impedances of both the conical horn and the wedgeshaped horn at their throats is approximately equal to the characteristic acoustic impedance of the medium.

3. Image-Sharpening Circuit and Sharpness of Acoustic Image

In the case of a radiation beam which is not narrow enough to produce a sharp image in a scanning system, the sharpness of the image can be improved by an electronic circuit. For the purpose of illustration, a small object with a flat reflection surface will be considered as a target for a single transducer scanning device, as shown in Figure 11.

When the center of the beam of the transducer reaches the position $x_{0}$ at time $t_{o}$ during the scanning process, weak reflections start from $x_{1}$, the edge of the object, due to the edge of the radiation lobe. The reflected energy will increase until the time that the center of the beam hits the center of the object (See Figure 12). The last reflected wave will be obtained from another edge $x_{2}$ at time $t_{1}$ when the center of the beam is at the position $x_{3}$. If the total reflected sound energy is read out on the receiving system, the width of the object will appear as $x_{3}-x_{0}$ instead of $x_{2}-x_{1}$. However, if there is a gate circuit in the receiving system and the gate opens only during the period when the center of the beam sweeps from $x_{1}$ to $x_{2}$, the readout equipment will show only the dimension of the object, that is, $x_{1}$ to $x_{2}$. 


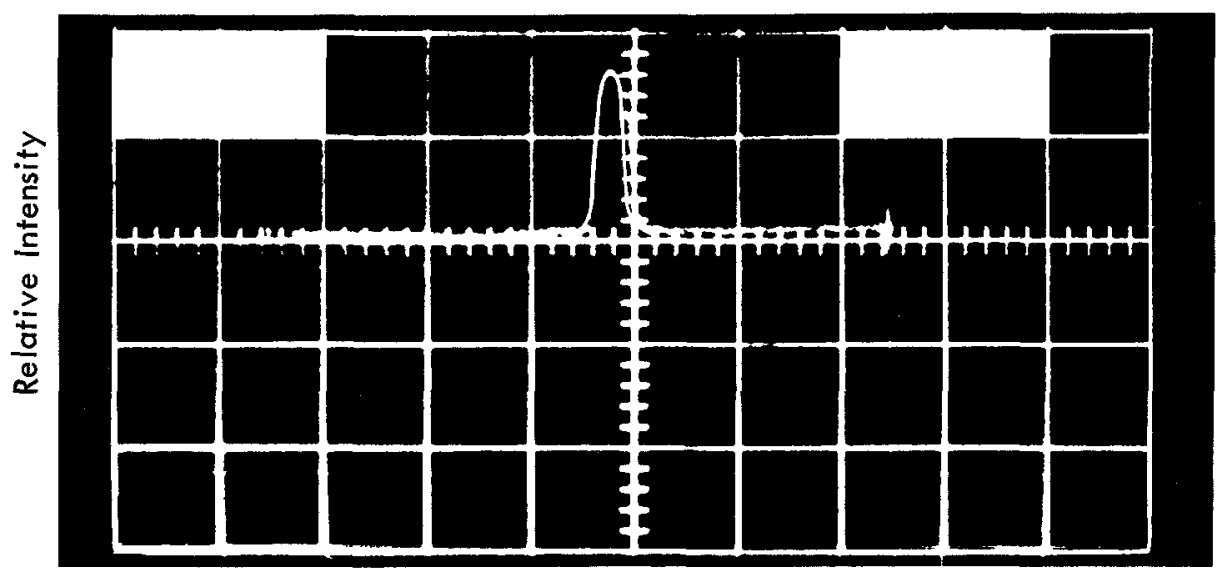

Angles, $5^{\circ}$ Major Division

FIG. 10 A TYPICAL REFLECTION PATTERN FROM A STEEL BAR

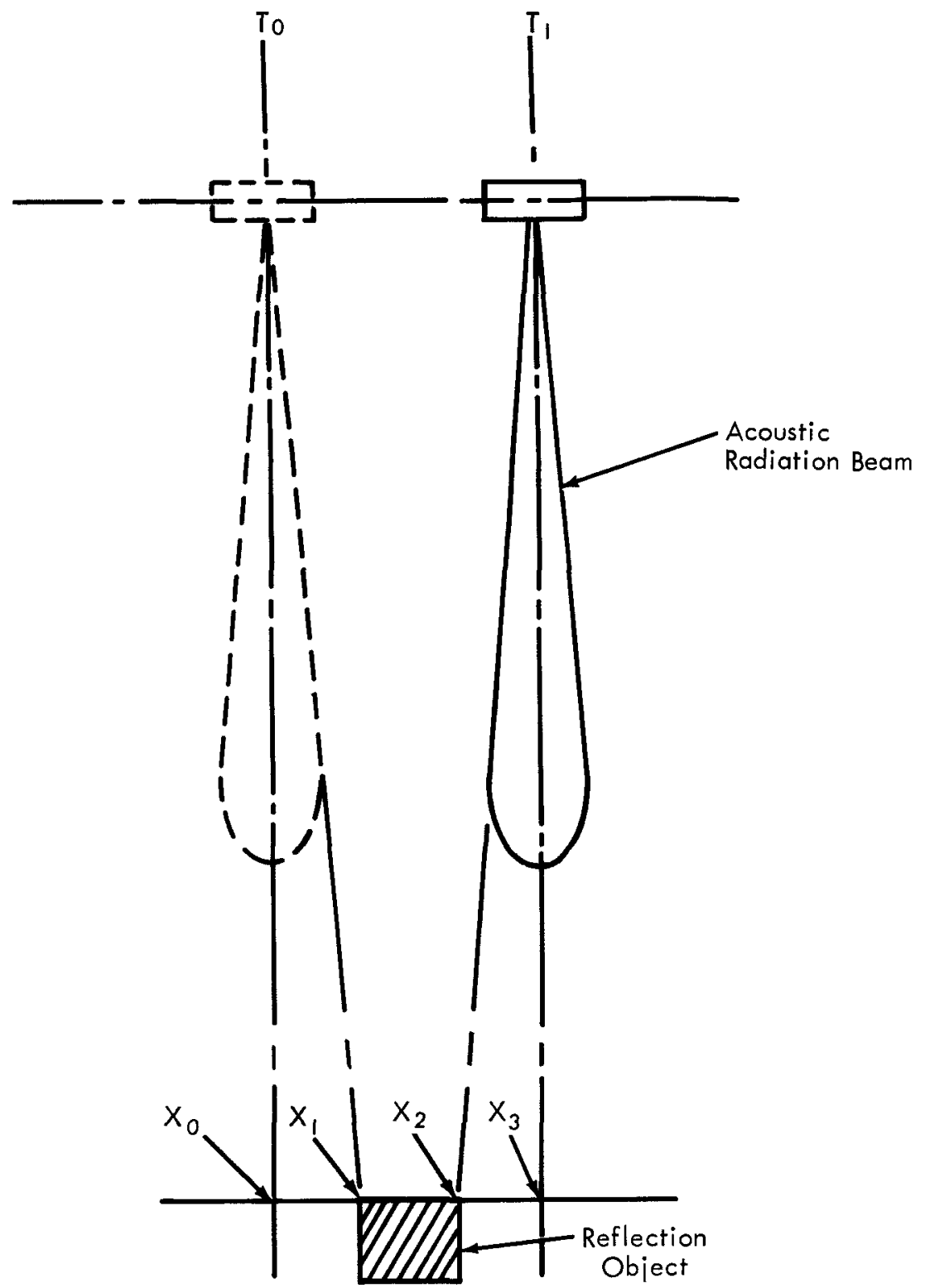

FIG. 11 REFLECTION FROM OBJECT ILLUMINATED BY MOVING RADIATION BEAM 

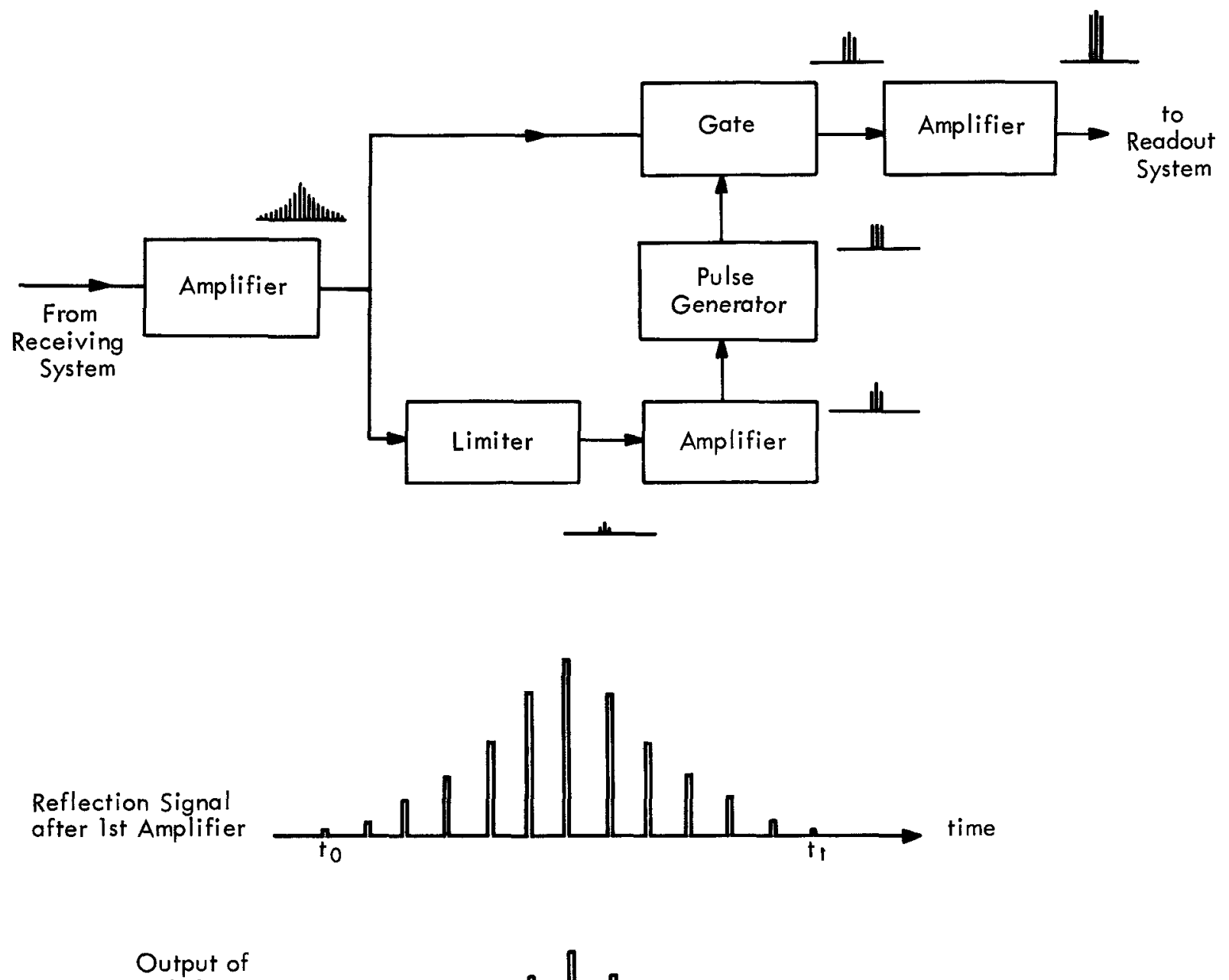

Limiter

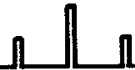

Output of Pulse Generator

几பட

Output of

Final Amplifier through Gate

FIG. 12 ILLUSTRATION AND BLOCK DIAGRAM OF IMAGE-SHARPENING CIRCUIT 
The control of the open period of the gate can be achieved by an amplitude limiter which permits only the stronger signal to pass, and by a pulse generator synchronized by the signals from the limiter through the amplifier for triggering the gate circuit.

As shown in Table V, for the case when the output of the receiver is 85 volts and the limiting level of the limiter is set at 83 volts, the sharpness of the image will be the same as that obtained from a $2^{\circ}$ beam width. Figure 13 is a plot of voltage vs transducer position, and illustrates the principle of defining the shape of an object by its shadow. A brass concave cylinder having a 6-foot radius was installed in a tank of water. The transducer was mounted approximately 3 feet from the brass reflector, and a $1 / 2$-inch aluminum cylinder was placed between the reflector and the transducer, 15 inches from the transducer and at zero aximuth. It will be noted that if the limiting signal is one volt, the gate will be shut off while the transducer moves between $-0.9^{\circ}$ and $+1^{\circ}$. Thus, the readout equipment will define the shape of the aluminum cylinder from its "shadow" cast upon the reflector.

\section{Description of Complete Systems}

The ultrasonic-pulse technique is the most convenient for singlenarrow-beam scanning. A functional diagram of a complete system which provides the range, position, and image of the object is shown in Figure 14. The range of the target obtained from the separation between transmitting pulse and the echo on the sweep of the oscilloscope is called A-scan. The image of the object printed at the proper position on the paper of the recorder is called C-scan, where the beam of the transducer successively scans the object line by line. In this process the movements of the transducer and the pen of the recorder are synchronized. When the transducer is rotated rapidly, the horizontal and vertical axes on the oscilloscope represent distance and direction, respectively. This is called B-scan.

As shown in Figure 14, the synchronization pulse generator provides synchronization between the pulsed oscillator, the sweep of the oscilloscope, and the multivibrator for the main gate circuit. The transducer is driven by the pulsed, oscillating voltage from the pulsed oscillator through the power amplifier. The receiving signal, after amplifying and detecting, is fed into the main gate circuit. The open duration of the gate is controlled by the pulse width of the pulse generator which is triggered by a delay pulse obtained from the multivibrator, differential, and limiting circuits. The delay time is variable and set to accept the reflected signals of interest. The signal will be displayed on the oscilloscope and recorder through the image-sharpened circuit discussed in the previous section.

For B-scan, except for the oscilloscope, the circuit remains the same. The electron beam of the cathode-ray tube is modulated by the receiving signals, and the sawtooth waves generated from the potentiometer on 


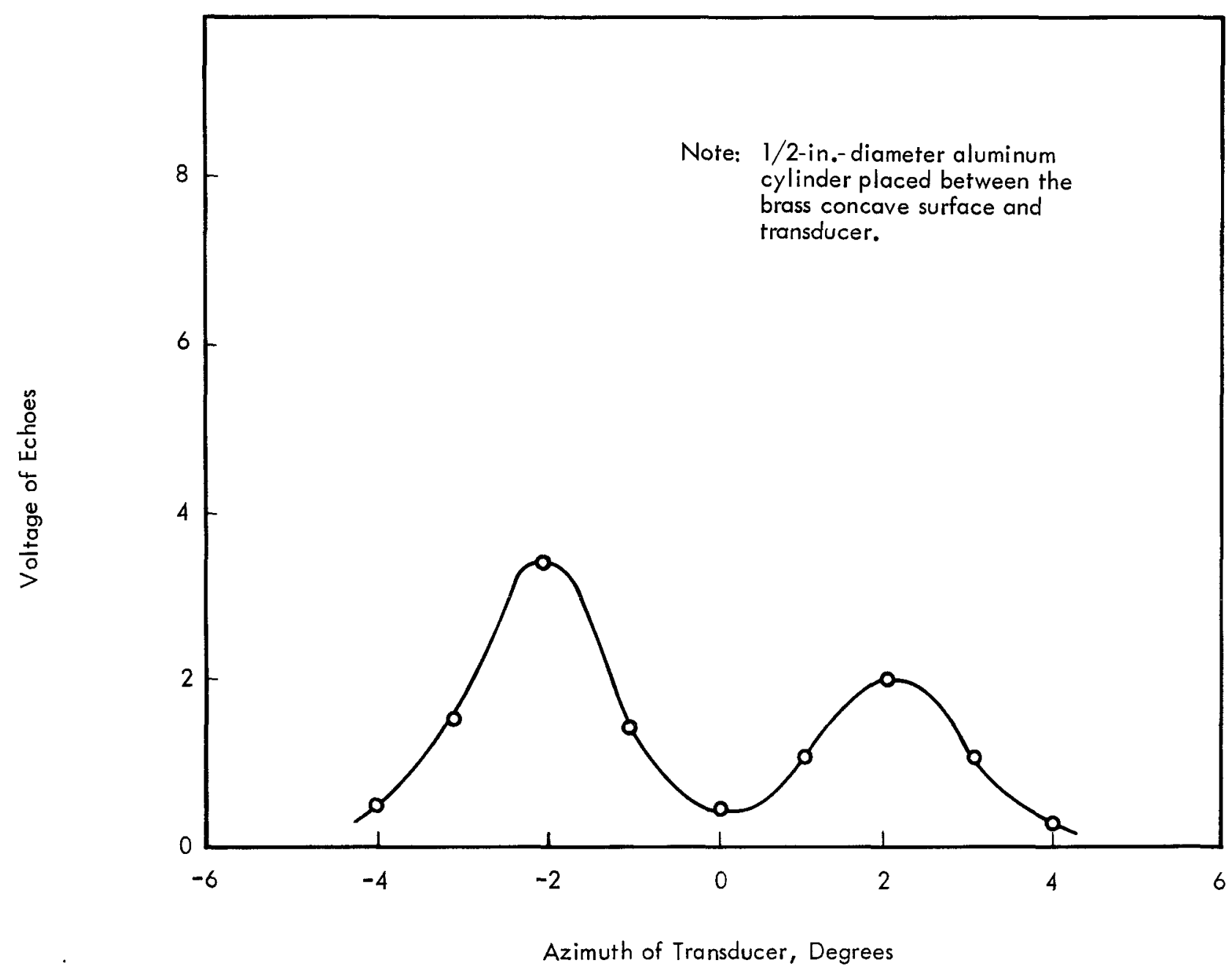

FIG. 13 ECHOES FROM BRASS CONCAVE SURFACE 


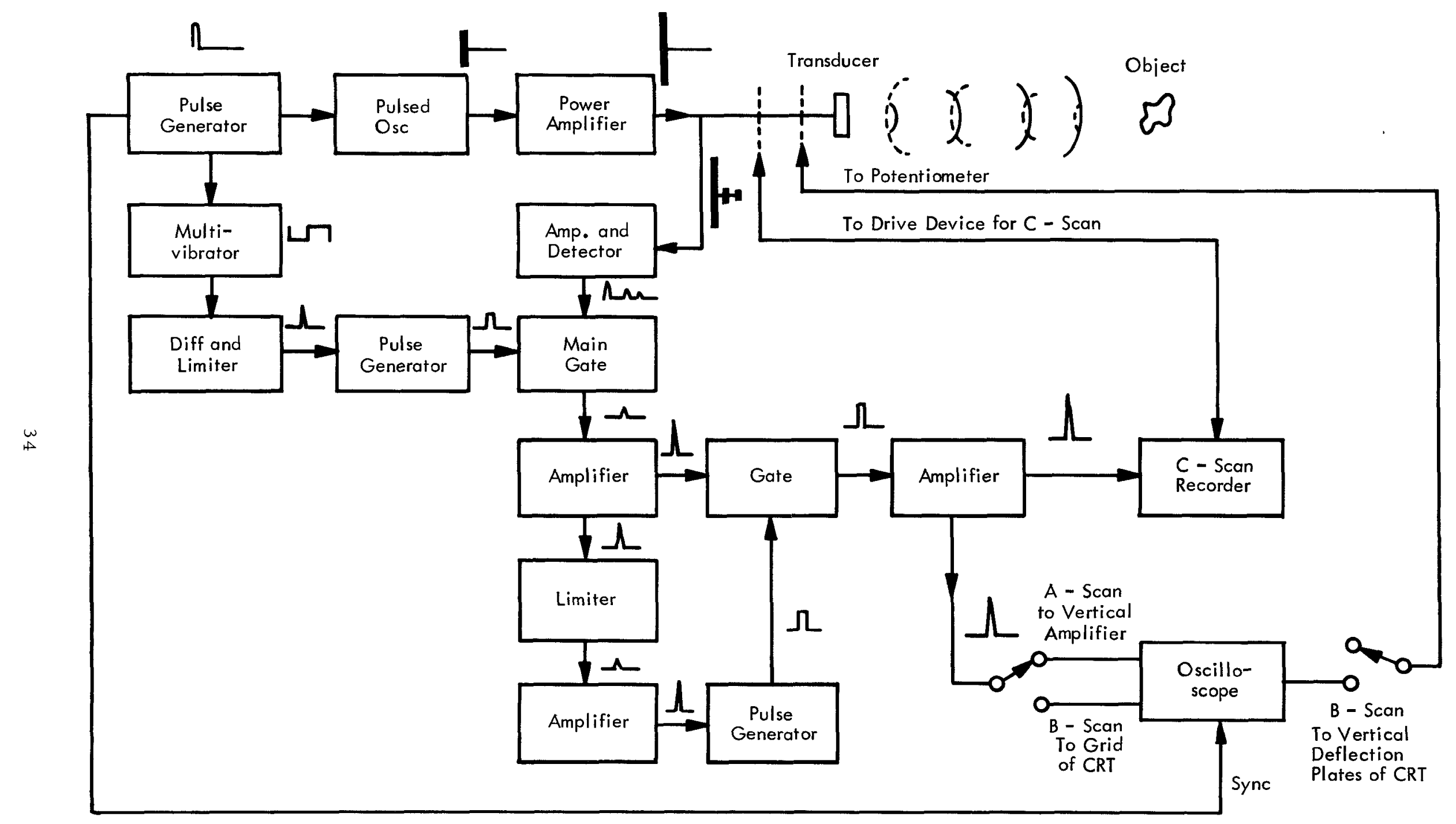

FIG. 14 FUNCTIONAL DIAGRAM OF ULTRASONIC SCANNER 
the transducer, due to the rotation of the transducer, are applied to the vertical deflection plates.

The minimum distance and the resolution of the distance in the pulse modulation system are determined by the pulse width of the transmitting pulse and recovery time and rise time in the receiving system. If the pulse width is $1 \mu \mathrm{sec}$, the recovery time and rise time are on the order of $10^{-3} \mathrm{\mu sec}$; then the minimum distance, in $600 \mathrm{~F}$ sodium, will be about $0.048 \mathrm{inch}$. The minimum distance is inversely proportional to the minimum carrier frequency.

If the magnetic deflection cathode-ray tube is used instead of the electric deflection cathode-ray tube, the B-scope will be replaced by a scope, such as the PPI used in radar. In this system, the time base starts from a fix point center of the scope, lies in radial direction, and rotates synchronously with the rotation of the transducer.

\section{B. ACOUSTIC IMAGE CONVERTERS}

\section{Review of Acoustic Image Converters}

Electronic acoustic methods for transforming acoustic images into visible ones have been used in the past, usually in room temperature water. The electronic acoustic converter was first conceived in 1935; the classic patent is that of Sokolov. 17 Oshchepkov, Rozenberg, and Semennikov constructed a unit in 1955 which is notable for having solved the problem of sealing a face plate of piezoelectric ceramic to the body of the cathode-ray tube. 18 The theory of operation is covered by Semennikov. 19, 20 Other converters have been built by Prokhorov, 21 Freitag and Martin, 22 Smith, 23 and Lawrie and Feith. 24 E. G. Goldman in his work with acoustic image converters developed a quartz target pickup tube with pulsed ultrasonics instead of continuous waves. 25 Jacobs and others 26 used an electron multiplier to increase the sensitivity of the acoustic image converter (AIC).

Figure 15 shows a method of forming an ultrasonic image and its conversion into a visible image. 21 A beam of plane ultrasonic waves is incident from a transducer upon the examined object which is located, for example, in a liquid medium. Due to the absorption and reflection of the sound waves that strike the object, an acoustic shadow is formed beyond the object. The acoustic shadow is the region of the ultrasonic field in which the ultrasonic intensity has been considerably weakened. If the ultrasonic wavelength is less than the dimensions of the object, the shape and dimensions of the acoustic shadow will define the shape and dimensions of the object with a definite accuracy.

The ultrasonic lens projects this shadow image into any region of the piezoelectric receiving plate. With the object, the lens, and the piezo- 


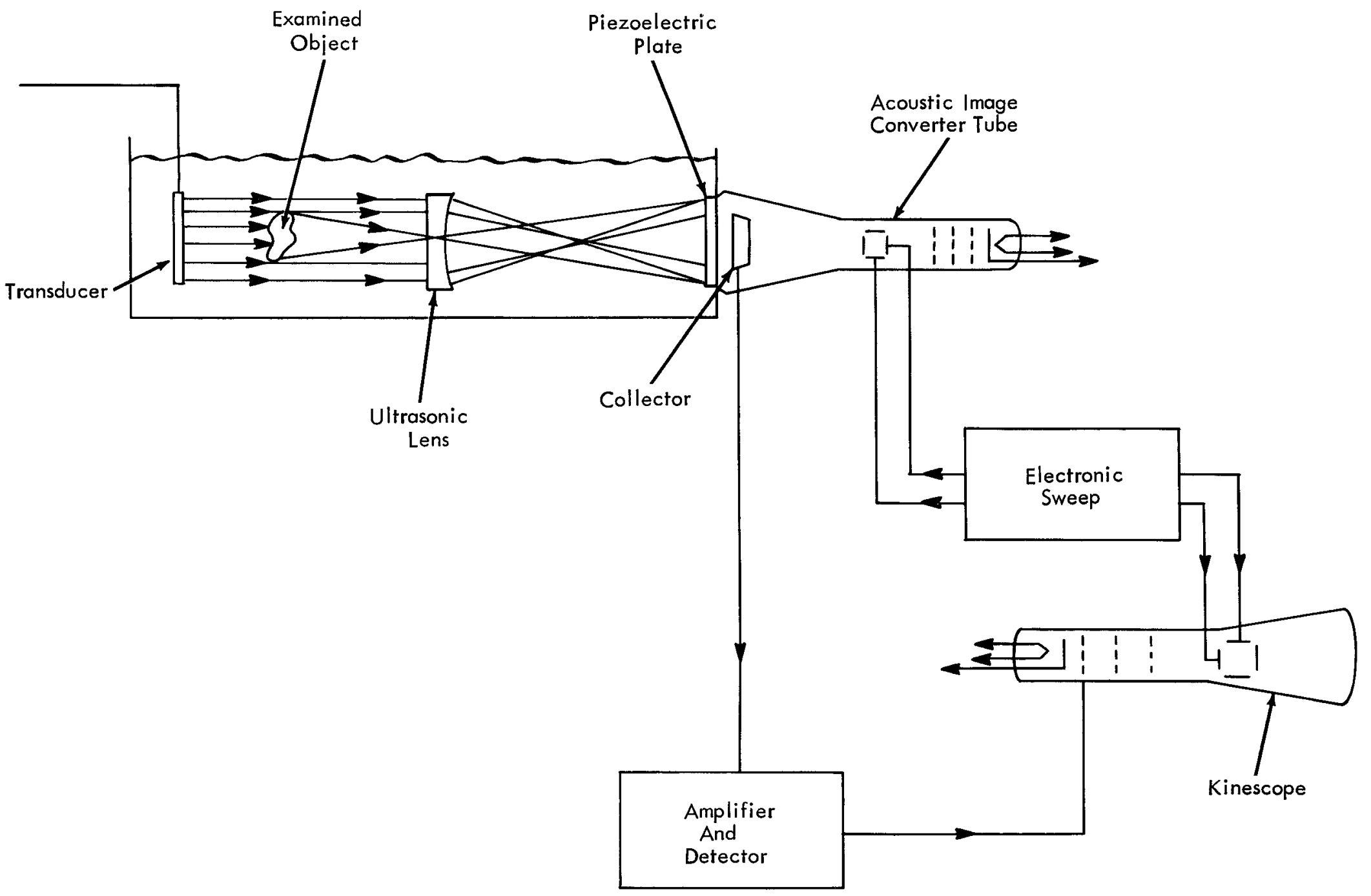

FIG. 15 TYPICAL ACOUSTIC IMAGE CONVERSION SYSTEM 
electric plate appropriately placed in respect to one another it is possible to obtain a magnified or diminished shadow image of the object. It is also possible to operate from rays which are reflected from the object; then the ultrasonic image of the object is obtained directly on the surface of the piezoelectric plate.

The ultrasonic image is converted into a series of electrical signals by the acoustic image converter tube. In contrast to a cathode-ray tube, the AIC has a piezoelectric target (a quartz plate). The external side of the plate is covered with a layer of silver and is grounded. An additional collector electrode is placed near the inside surface of the plate for collecting the secondary electrons which are knocked out of the target by the electron beam.

The ultrasonic beam which has passed through both the medium containing the object and the lens has a definite intensity distribution (pressure distribution) over its cross section. This distribution depends upon the shape and structure of the ir radiated object. When such an ultrasonic field impinges upon the receiving piezo-plate, the individual sectors of the plate will be subjected to a variable-amplitude alternating ultrasonic pressure. Due to the piezoeffect, piezoelectric charges are formed on the surface of the target. These charges correspond to the pressure distribution in the cross section of the ultrasonic beam; thus, the ultrasonic image is converted into a piezoelectric image.

The next feature of the over-all conversion consists of converting this piezoelectric image into a series of electric signals which are successively reproduced into a visible image. This is accomplished by means of an electronic sweep. The electron beam successively scans the surface of the piezo-plate line by line, thus forming a television raster. Since the piezoelectric target is a good dielectric, the sole source of current in it is the primary electronic beam, and the sole current leakage from it consists of the secondary electrons. In the given case, the variation of the change (potential) of the target surface is achieved piezoelectrically due to the effect produced by the ultrasonic image. Here a useful high-frequency signal is formed across the load in the collector circuit due to the variation in the number of secondary electrons which leave the surface of the piezoelectric target. After amplification and detection, this signal is fed to the control electrode of a second cathode-ray tube, i. e., the kinescope. If the movement of the electron beam in the tube is synchronous, the image of the object which has been irradiated by the ultrasonic waves will be reproduced on the screen of the kinescope.

\section{Sensitivity of Acoustic Image Converters}

At the present time, many different methods have been cited for visualizing acoustic fields. 27 Most of the methods are based on the direct 
conversion of the acoustic wave energy into an optical image (direct image converters). Although simple, these methods have low sensitivities. Since the threshold value of the acoustic field intensity must be no less than $10^{-3}$ $\mathrm{w} / \mathrm{cm}^{2}$, at present they are used only in laboratory studies of acoustic fields.

Much more promising are methods of electronic acoustic image conversion. Utilization of the electron multiplier can increase the sensitivities of electronic acoustic image converters. 26 However, the ultimate sensitivity is limited by the ability to recognize a change in potential on the surface of the target of AIC. It has been determined, both through measurements on the piezoelectric surface and through the use of a multi-electrode target structure whose differential potential was controllable, that the minimum discernible potential on the target is in the order of $50 \mathrm{mv}$, this limit being set by variations in the energy of the secondary emission electrons.

Previous investigators 19 have measured the transconductance of the secondary emission beam and found it to lie in the range of $6 \times 10^{-8}$ amperes per volt per microampere of beam current, which means that the secondary emission beam is modulated in the order of 6 per cent per volt variation in induced voltage. Using this value of beam transconductance coupled with the figure of $50 \mathrm{mv}$ set by the spread in scanning secondary electron velocities, the minimum sound field that is detectable at a frequency of 500 kc lies in the range of $10^{-7}$ watts per $\mathrm{cm}^{2}$. Much of the previous work has been done at about $10^{-6}$ watts per $\mathrm{cm}^{2}$.

\section{Considerations for Operation in Liquid Sodium}

Quartz and barium titanate have previously been used in AIC. Other semiconducting materials have been investigated to determine their suitability for use in an ultrasound-sensitive camera tube in which the resistivity change of the target material is used to convert the acoustical image into an electrical charge pattern. 27 Of the materials studied, $\mathrm{CdS}: \mathrm{Cu}$ yeilded the best results.

From the standpoint of resolution it would be desirable to operate at higher frequencies. For example, the wavelength of a 2-Mc ultrasonic field in liquid sodium at $600 \mathrm{~F}$ is about $0.121 \mathrm{~cm}$, while at $20 \mathrm{Mc}$ it is onetenth that value. However, as the ultrasonic frequency is increased, attenuation problems and the minimum driven sound field for the AIC become more significant. For general inspection purposes, frequency ranges between $1 \mathrm{Mc}$ and $7 \mathrm{Mc}$ appea $\mathrm{r}$ to be optimum. Continuous wave ultrasonic imaging equipment operating at $1.9 \mathrm{Mc}$ has been used for the inspection of thin metallic samples in water at room temperature. 28

The electronic acoustic imaging method exhibits higher sensitivities when compared to other methods. Therefore, from the standpoint of attenuation, no problems exist for the power requirement using liquid sodium as the ultrasonic transmission medium. 
In order to obtain a vacuum seal in liquid sodium, a metal acoustic window and a vacuum seal in the region of lower temperatures can be employed, as shown in Figure 16. 


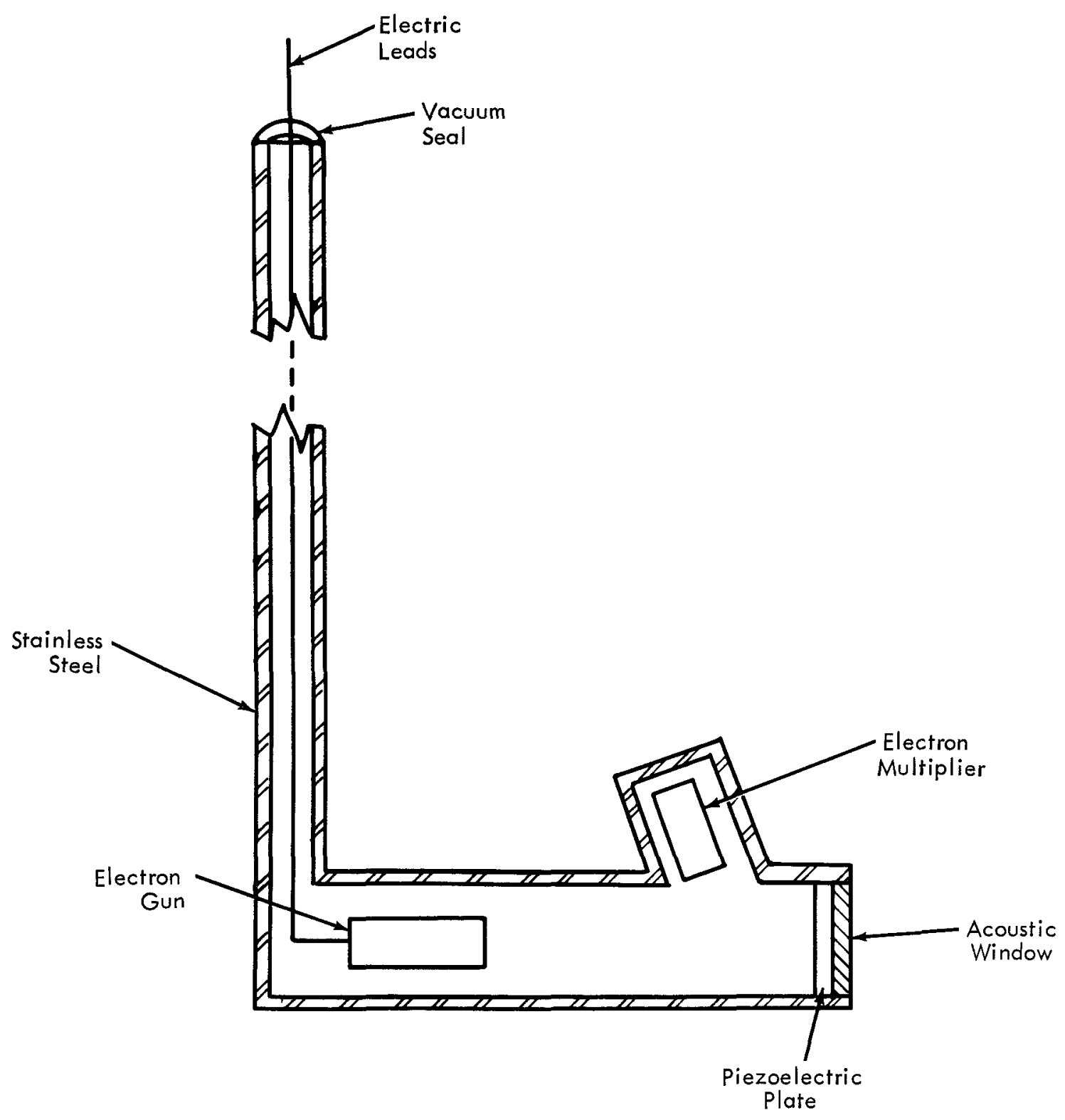

FIG. 16 ACOUSTIC IMAGE CONVERTER FOR OPERATION IN LIQUID SODIUM 


\section{APPLICATIONS FOR SCANNER SYSTEMS}

\section{A. APPLICATIONS FOR A-SCAN AND B-SCAN DISPLAYS}

\section{Locating Objects}

The application of ultrasonic beam orientations for locating objects in liquid sodium can be made without difficulty. By use of the reflected sound energies from an object, the object can be located and the distance from the transducer can be defined by the A-scan display. By using the B-scan, a second dimension can be added to the presentation of the object by alternately scanning the object, line by line. In order to locate an object in an area with a complicated background--for example, a subassembly that has been inadvertently dropped to the bottom of a reactor vessel--drawings of the structure must be available so that sources of extraneous reflections can be identified.

\section{Distance and Thickness Measurements}

Because of the acoustic impedance mismatching at both surfaces of a metal plate in liquid media, two reflections, one from each surface, appear on the oscilloscope screen in the A-scan display. Therefore, the thickness of a metal plate can be determined by the separation of the two reflected pulses on the oscilloscope screen. Similarly, distances can be distinguished by the reflections from two or moreobjects, or by the reflections resulting from the movement of an object.

The thickness of an object can also be determined by the measurement of an rms voltage of a rectangular wave generated by a multivibrator triggered by the two reflection pulses from the surfaces of a plate. The minimum thickness that can be read is determined by the pulse width and the velocity of sound in the metal plate. The estimated minimum thickness that can be accurately read is 0.030 inches for steel.

\section{Controlling the Movement of an Object}

Automatic control for fuel handling can be achieved by the utilization of reflected sound waves from the subassemblies that are being moved. A voltage proportional to the distance between the transducer and the subassembly can be used to operate the handling mechanism. The transducer can be programmed to move along the desired path for the subassembly. As 'the transducer moves in a direction that causes a reduction of signal because of reduced sound reflections from the subassembly, the handling mechanism can be made to follow the transducer orientation. 


\section{B. APPLICATIONS FOR C-SCAN AND THE ACOUSTIC IMAGE CONVERTER}

\section{Identifying Subassemblies}

An identification mark, in the form of the number seven on the head of a subassembly, is shown in Figure 17. In Figure 17a the seven is formed by a rectangular groove; in Figure $17 \mathrm{~b}$ it is formed by a triangular or sloped groove. In each case the acoustic reflections from the surface of the grooved number will differ from those obtained from the smooth surface of the subassembly head. In addition, different acoustic reflections will be obtained from the different types of grooves.

The reflected sound energy from the rectangular groove, Figure 17a, will arrive at the transducer later than the reflected energy from the smooth surface of the subassembly head. By proper utilization of the gate circuit, only the reflected energy from the bottom of the groove will be displayed on the C-scan recorder. Conversely, the energy from the triangular groove, Figure 17b, will not be reflected back to the transducer because of the angle of incidence. Thus, the groove will appear as a shadow on the Cscan recorder.

\section{Obtaining Images of Objects}

By utilizing the reflected energy from a normal incident beam striking an object, i. e., normal reflections from the object, or by utilizing the object to absorb and reflect a part of the energy, thus creating an acoustic "shadow" against an illuminated background, images of objects can be obtained by C-scan systems. If an acoustic image conversion system, such as previously discussed, is used to convert acoustic images into visible ones, the absorption and reflection phenomena of objects and background will be of no consequence.

\section{Defining the Orientation of Objects}

If normal reflections from an object or background cannot be utilized to outline the image of an object, and if the image conversion system cannot be utilized because of space limitations, the orientation of an object may be determined by means of identifying marks. For example, a small mark, such as an arrow, would be stamped on the surface of the object before installation. The orientation of the object would be defined by locating and outlining the mark, even though the shape of the object could not be defined. 

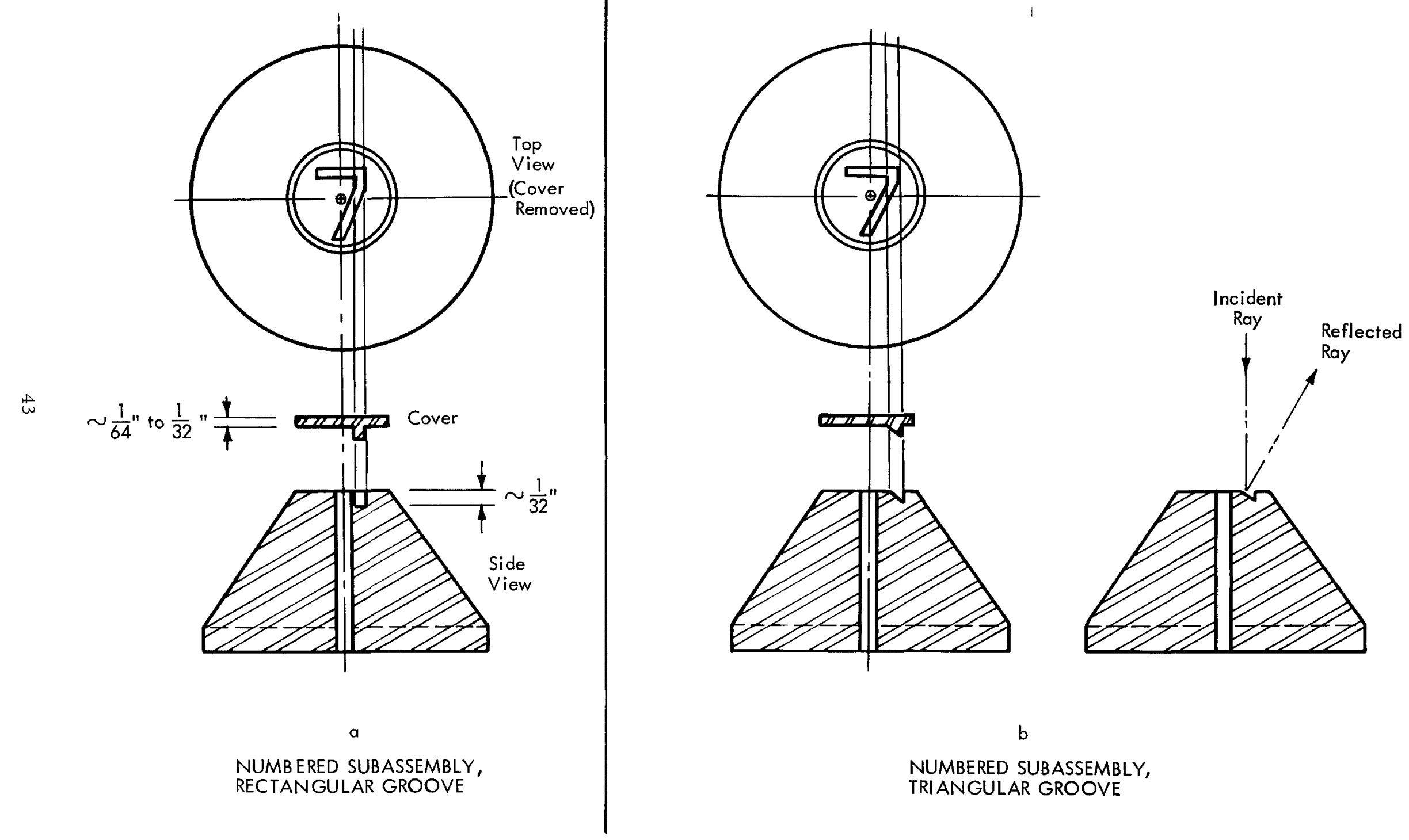

FIG. 17 IDENTIFICATION MARKS ON SUBASSEMBLIES 


\section{Under Sodium Nondestructive Testing}

The applications of nondestructive testing will be possible from under sodium sonics, providing material examinations of components that cannot be readily removed from a system. 
REFERENCES

1. Kleppa, O.J., J. Chem. Phys., 18:1331-6 (1950).

2. Pochapsky, T.E., "The Temperature Variation of the Compressibility of Molten Sodium," Phys. Rev., 84:553-8 (1951).

3. Sittig, M., Sodium - Its Manufacture, Properties and Uses, Reinhold Publishing Corporation, New York; Chapman \& Hall, Ltd., London, 1956.

4. Faran, J.A., J. Acoust. Soc. Am., 23:405 (1951).

5. See, for example, Carlin, Benson, Ultrasonics, McGraw-Hill Book Company, New York, 1960.

6. Herafeld, K. F. and Litovitz, T.A., Absorption and Dispersion of Ultrasonic Waves, Academic Press, Inc., New York, 1959.

7. Stokes, G., Trans. Cambridge Phil. Soc., $8: 287$ (1845).

8. Kirchoff, G., Poggendorff's Ann. Phys., 134:177 (1868).

9. Final Report on AEC-Sponsored Project, Contract No. At(11-1)-865, USAEC Report APDA-180, Atomic Power Development Associates, Inc., Detroit, Michigan, to be published.

10. Fox, F.E., and Rock, G. D., Phys. Rev., 70:68 (1946).

11. Mason, W.P., Physical Acoustics, Vol. 1, Part A, Academic Press, New York and London, 1964.

12. Ibid., p. 204, citing Berlincourt, D., Cmolik, C., and Jaffe, H., Proc. IRE, 48:220 (1960).

13. Ibid., citing Brown, C.S., Kell, R.C., Taylor, R., and Thomas, L. A., Proc. Inst. Elect. Engrs. (London), 109:Pt. B, No. 43, 99 (1962).

14. Hewter, T.F., and Bolt, R.H., Sonics, John Wiley \& Sons, Inc., New York; Chapman \& Hall, Ltd., London, 1955.

15. O'Neil, H.T., J. Acoust. Soc. Am., 21:516-526 (1949). 
16. McKinney, C.M., and Owens, W.R., J. Acoust. Soc. Am. 29:744 and 940 (1957).

17. Sokolov, S., Means for Indicating Flaw in Materials, U.S. Patent No. 2, 164, 125, June 27, 1939.

18. Oshchepkov, P.K., Rozenberg, L. D., and Semennikov, I. B., "An Electronic-Acoustical Transducer for the Visualization of Sound Images," Soviet Physics - Acoustics, 1:362 (1955).

19. Semennikov, I. B., "A Study of Acoustic Image Converters, "Soviet Physics - Acoustics, $4: 72$ (1958).

20. Semennikov, I. B., "Certain Aspects of the Operation of an ElectronicAcoustic Image Converter," Soviet Physics - Acoustics, 7:56 (1961).

21. Prokhorov, V.G., "The Problem of Converting an Ultrasonic Image into a Visible One," Soviet Physics - Acoustics, 3:272 (1957).

22. Freitag, W., and Martin, H. J., Acustica, 8:197 (1958).

23. Smith, Engineer, 209:348 (February 27, 1959).

24. Lawrie, W.E., and Feith, K.E., Armour Research Laboratories.

25. Goldman, R. G., "Electronic Acoustic Image Converter," J. Acoust. Soc. Am., 34:514 (1962).

26. Jacobs, J.E., Berger, H., and Collis, W. J., "An Investigation of the Limitation to the Maximum Attainable Sensitivity in Acoustic Image Converters," 1962 Ultrasonic Symposium (IRE Professional Group on Ultrasonic Engineering), New York, Nov. 1962. Published in IEEE Transactions of the Professional Technical Group on Ultrasonic Engineering, Vol. UE-10, No. 2, September 1963.

27. Nghiem Ung Phan, "The Application of Television Scanning Techniques to the Problem of Visualizing Ultrasound Images, " unpublished M.S. Thesis, Northwestern University, 1961.

28. Berger, H., and DiNovi, R. A., "Angular Positioning of Thin Metallic Samples for Optimum Continuous-Wave Ultrasonic Imaging," J. Acoust. Soc. Am. , 36:2053 (1964). 


\section{DIS TRIBU TION LIST}

No. of Copies

United States Atomic Energy Commission

7

Fred C. Mattmueller

Chicago Operations Office

1

George H. Lee

Chicago Operations Office

Sheldon Meyers

Military Compact Reactors Project

John Holliday

San Francisco Operations Office

C. W. Richards

Canoga Park Area Office

Joseph Dissler

New York Operations Office

AEC Headquarters

Division of Reactor Development \& Technology

Glen W. Wensch, Liquid Metal Cooled Reactors Branch Ralph H. Jones, Liquid Metal Cooled Reactors Branch

J. A. Lieberman, Nuclear Safety

S. A. Szawlewicz, Research \& Development Branch

J. M. Simmons, Fuels \& Materials Development Branch

A. Van Echo, Fuels \& Materials Development Branch

N. Grossman, Engineering Development Branch

W. R. Kornack, Military Compact Reactors Branch

M. J. Whitman, Reactor Experiments Branch

Oak Ridge National Laboratory

$\begin{array}{ll}1 & \text { J. H. Devan } \\ 1 & \text { H. W. Savage } \\ 1 & \text { D. Gardiner } \\ 1 & \text { J. White } \\ 1 & \text { R. E. MacPherson }\end{array}$


No. of Copies

Brookhaven National Laboratory, Upton, Long Island, New York

$1 \quad$ O. E. Dwyer

$1 \quad$ C. Klamut

1 L. Newman

1 A. Romano

$1 \quad$ K. Hoffman

Argonne National Laboratory, Argonne, Illinois

1 Sherman Greenberg

1 Leroy Kelman

$1 \quad$ Fred Smith

1 W. R. Simmons

$1 \quad$ R. Bane

$1 \quad$ K. Kuczen

Los Alamos Scientific Laboratory, Los Alamos, New Mexico

1 W. R. Wykoff

1 G. Waterbury

1 L. E. Whinery

Miscellaneous

3 D. T. Eggen

Atomics International

3 Karl Cohen

General Electric Company

$1 \quad$ Phillip S. Otten

Baldwin-Lima-Hamilton Corporation

1 Robert C. Werner

Mine Safety Appliance Research

1 J. H. Wright

Westinghouse Corporation

$1 \quad$ Paul B. Probert

Babcock \& Wilcox Company

1 C. A. Barrett

NASA, Lewis Flight Propulsion Laboratory 
No. of Copies

1

Robert S. Carey

Aerojet-General Corporation

$1 \quad$ Kurt Goldman

United Nuclear Corporation

1 E. Astley

Battelle Northwest

US-EURA TOM FAST BREEDER REACTOR EXCHANGE

10 Prof. W. Haefele

Karlsruhe, Germany

10

G. Vendryes

CEN, France

10

Arnold de Stordeur

EURA TOM, Brussels, Belgium

4

Ing. F. Pierantoni

CNEN, Italy

$5 \quad$ Stephen Lawroski

Argonne National Laboratory

2 David B. Hall

Los Alamos Scientific Laboratory

$3 \quad$ Sidney Siegel

Atomics International

$1 \quad$ Arthur S. Griswold

Power Reactor Development Company

2

Alton P. Donnell

Atomic Power Development Associates, Inc.

2

Alfred Strasser

United Nuclear Corporation

1

C. H. Staub

MSA Research Corporation 
No. of Copies

1

Richard J. Gariboldi

USAEC/COO

2 Walter H. Zinn

Combustion Engineering, Inc.

1 Virginia D. Rose

Allis-Chalmers Manufacturing Company

November 1, 1965 